\title{
Containment Prospectus
}

for the

\section{TRUMPET \\ Experiments}

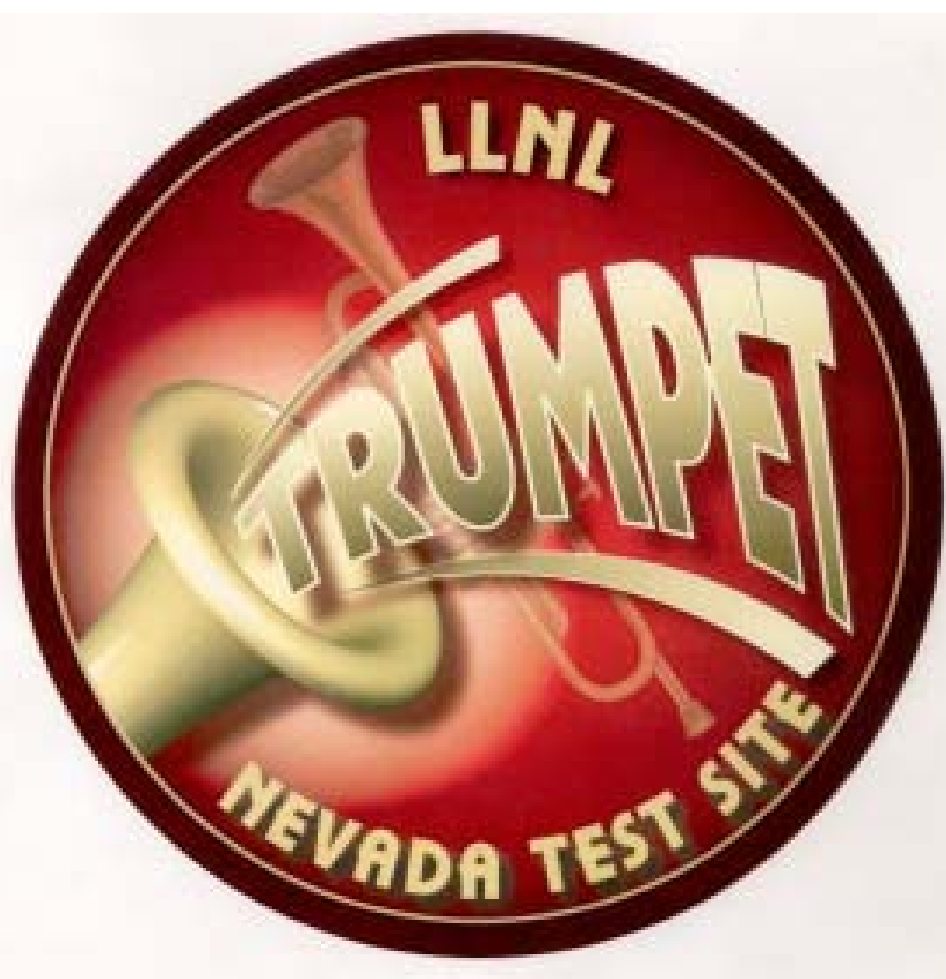

Gayle A. Pawloski

Containment Scientist

Lawrence Livermore National Laboratory

February 4, 2004

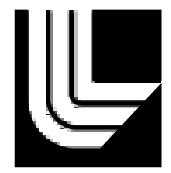


This document was prepared as an account of work sponsored by an agency of the United States Government. Neither the United States Government nor the University of California nor any of their employees, makes any warranty, express or implied, or assumes any legal liability or responsibility for the accuracy, completeness, or usefulness of any information, apparatus, product, or process disclosed, or represents that its use would not infringe privately owned rights. Reference herein to any specific commercial product, process, or service by trade name, trademark, manufacturer, or otherwise, does not necessarily constitute or imply its endorsement, recommendation, or favoring by the United States Government or the University of California. The views and opinions of authors expressed herein do not necessarily state or reflect those of the United States Government or the University of California, and shall not be used for advertising or product endorsement purposes.

This work was performed under the auspices of the U.S. Department of Energy by University of California, Lawrence Livermore National Laboratory under Contract W-7405-Eng-48. 


\section{Contents}

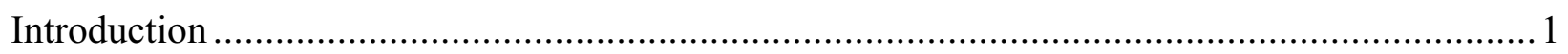

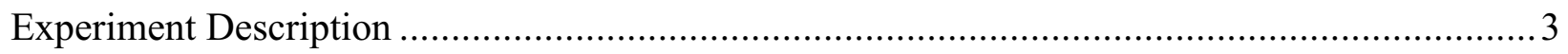

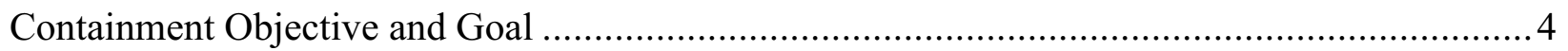

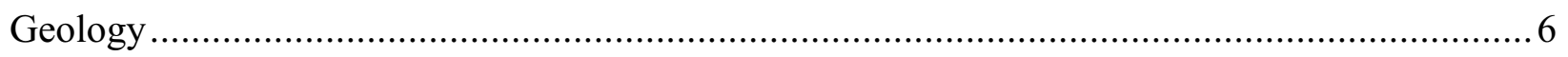

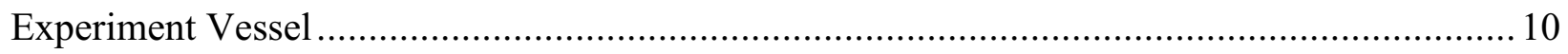

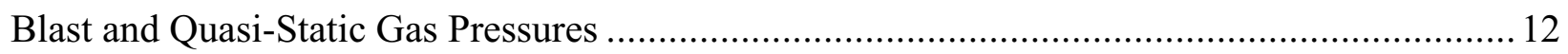

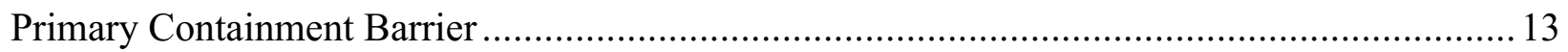

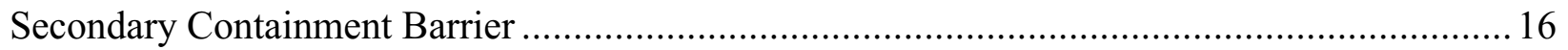

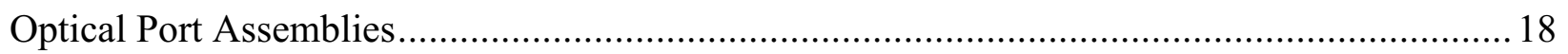

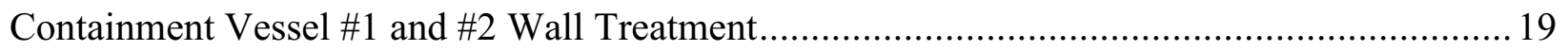

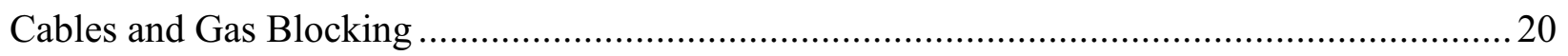

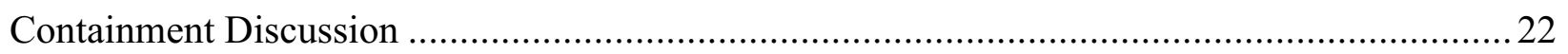

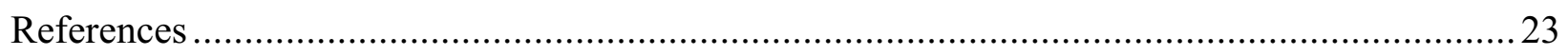

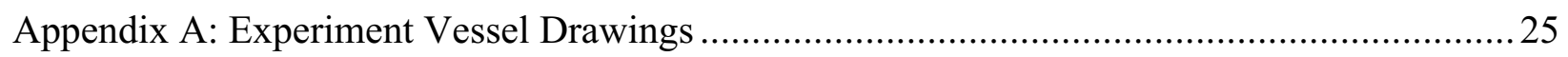

Appendix B: Primary Containment Barrier Drawings ......................................................... 41

Appendix C: Secondary Containment Barrier Drawings........................................................ 49

Appendix D: Optical Port Assembly Drawings .........................................................................5 
INTENTIONALLY LEFT BLANK 


\section{Containment Prospectus for the TRUMPET Experiments}

\section{Introduction}

TRUMPET is a series of dynamic subcritical experiments planned for execution in the U1a.102D alcove of the U1a Complex at the Nevada Test Site (NTS). The location of LLNL drifts at the U1a Complex is shown in Figure 1. The data from the TRUMPET experiments will be used in the Stockpile Stewardship Program to assess the aging of nuclear weapons components and to better model the long-term performance of weapons in the enduring stockpile.

The TRUMPET series of experiments will be conducted in an almost identical way as the OBOE series of experiments. Individual TRUMPET experiments will be housed in an experiment vessel, as was done for OBOE. These vessels are the same as those utilized for OBOE. All TRUMPET experiments will occur in the zero room in the U1a.102D alcove, which is on the opposite side of the U1a.102 drift from U1a.102C, which housed the OBOE experiments. The centerlines of these two alcoves are separated by only 10 feet. As with OBOE experiments, expended TRUMPET experiment vessels will be moved to the back of the alcove and entombed in grout. After the TRUMPET series of experiments is completed, another experiment will be sited in the U1a.102D alcove and it will be the final experiment in the zero room, as was similarly done for the OBOE series of experiments followed by the execution of the PIANO experiment.

Each experimental package for TRUMPET will be composed of high explosive (HE) and special nuclear material (SNM) in a subcritical assembly. Each experimental package will be placed in an experimental vessel within the TRUMPET zero room in the U1a.102D alcove.

The containment plan for the TRUMPET experiments utilizes a two-nested containment vessel concept, similar to OBOE and other subcritical experiments in the U1a Complex. The first containment vessel is formed by the primary containment barrier that seals the U1a.102D drift. The second containment vessel is formed by the secondary containment barrier in the U1a.100 drift. While it is likely that the experiment vessel will contain the SNM from the experiment, the containment plan for the TRUMPET experiments only assumes that the experiment vessel provides shock mitigation and serves as a sink for the heat produced by the detonation of the HE. It is possible that one or more of the experiment vessels may seep SNM into the zero room from a failure of a seal on the vessel.

This containment plan covers the entire series of TRUMPET experiments. At this time, we don't know exactly how many experiments will actually be conducted in the TRUMPET series. However, we know that the maximum planned number of experiments in the TRUMPET series is 20. This number may be modified on the basis of results obtained from each TRUMPET experiment. After the final experiment in the TRUMPET series is completed, a larger experiment 
will be conducted in the U1a.102D alcove. A separate containment plan will be developed and presented to the Containment Review Panel (CRP) for that larger experiment.

As with OBOE, this containment plan is intended to cover all TRUMPET experiments. We will not develop a separate containment plan for each experiment. Before each experiment we will present a statement to the CRP that each TRUMPET experiment falls within the parameters presented in this document. If an experiment falls outside the parameters in this document, a containment plan for that experiment will be developed and presented to the CRP for a full containment review.

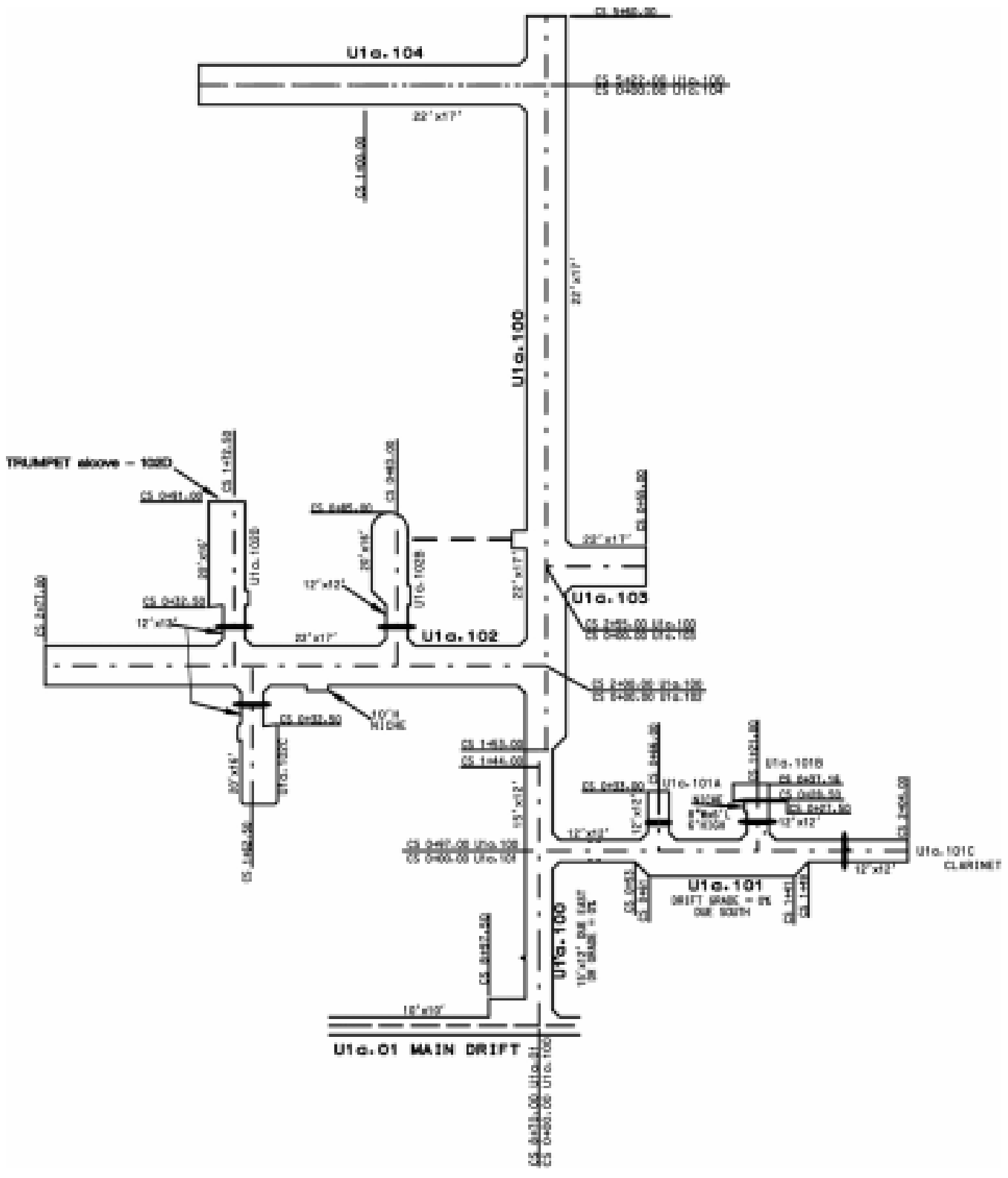

Figure 1. Location of LLNL drifts at the U1a Complex. 


\section{Experiment Description}

TRUMPET is a series of dynamic subcritical experiments to be executed in the U1a.102D alcove. Each experiment in the TRUMPET series will have assemblies of chemical $\mathrm{HE}$ and SNM. The assembly will be put inside an experiment vessel in the zero room approximately 8 feet from the primary containment barrier. The HE limit for an individual experiment in the TRUMPET series under this containment plan is 85 grams of LX-14 or its energy equivalent.

The essential containment features for each TRUMPET experiment are listed below. These are identical to those for the OBOE series of experiments, except that the design maximum HE limit was 65 grams for each experiment in the OBOE zero room.

1. HE weight is limited to a maximum of 85 grams of LX-14 or its equivalent.

2. Each experimental package will utilize an experimental vessel in the TRUMPET zero room.

3. The two-nested containment vessel concept as defined will be fielded.

Various diagnostics will be used on the TRUMPET series of experiments, and they will change over the experiments in the series. The diagnostics data from the experiments may be recorded either inside or outside the zero room depending on the experiment configuration. Some data may be recorded on film within the zero room. Data may be transmitted over electrical or fiber optic cables to recording instrumentation outside the zero room. Other data may exit the zero room through optical ports. 


\section{Containment Objective and Goal}

The LLNL containment objective for the TRUMPET experiments (and all LLNL subcritical experiments) is to assure that no SNM will be released to any uncontrolled environment as a result of the experiment. The specific TRUMPET containment goal is to confine all SNM to the zero room and/or the alluvium surrounding the zero room.

The TRUMPET containment design will use the time-tested concept of two nested containment vessels to assure this objective. The first containment vessel (Vessel \#1) includes the zero room in the U1a.102D drift, the primary containment barrier, and the alluvium surrounding the zero room. The second containment vessel (Vessel \#2) includes the volume of Vessel \#1, the volume of the U1a.102, U1a.101, and U1a.100 drifts inside the secondary containment barrier, the secondary barrier, and the alluvium surrounding these drifts. Figure 2 illustrates the concept of two nested containment vessels.

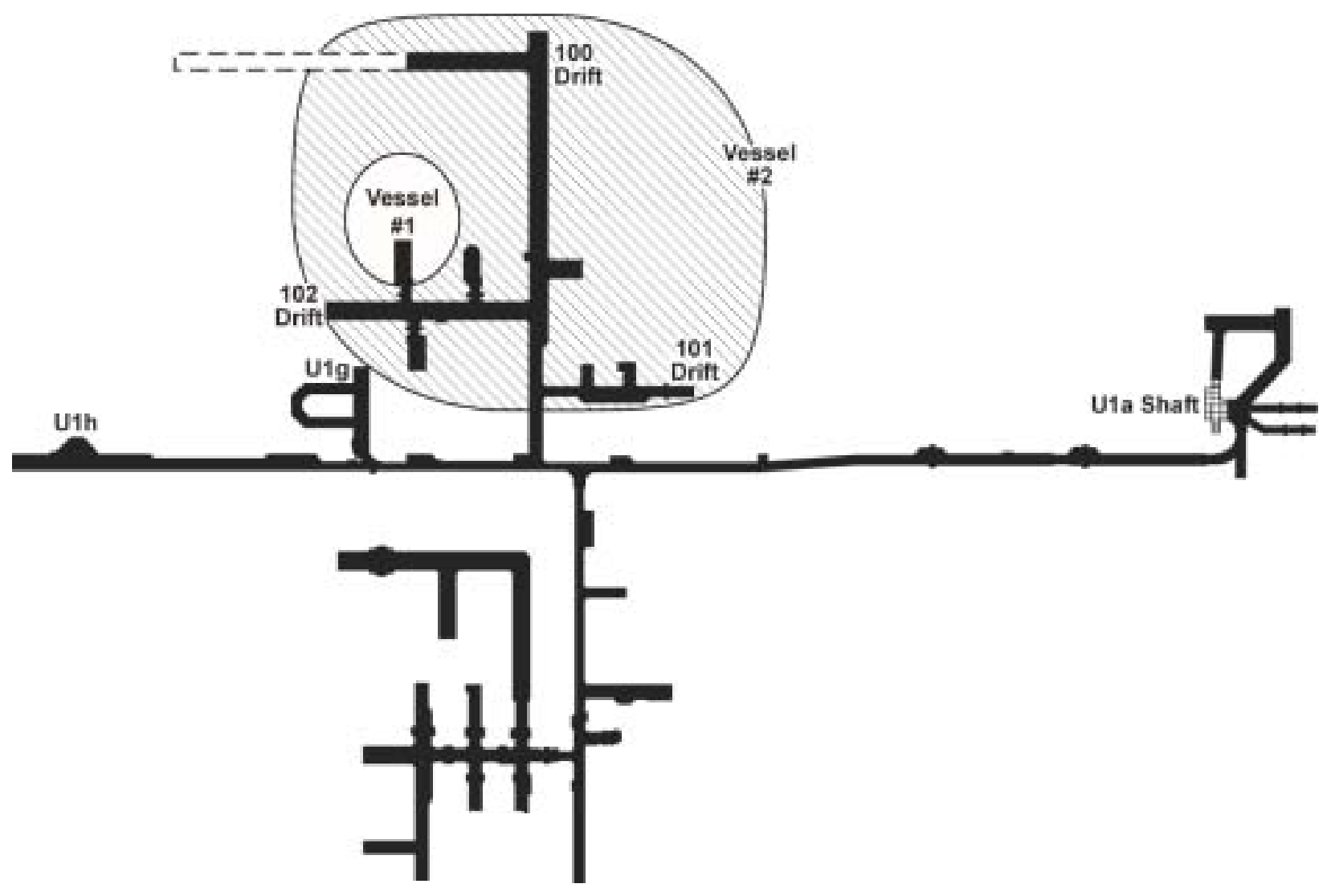

Figure 2. Illustration of the concept of two nested containment vessels. 
Each experiment in the TRUMPET series will be conducted within an experiment vessel, which will be installed in the zero room. After an experiment, the zero room may be reentered to gather diagnostics data and then to position another experiment in the zero room in preparation for another experiment in the TRUMPET series. An expended experiment vessel will never leave the zero room. It will be entombed in grout at the rear of the room. Therefore, if the TRUMPET containment goal is achieved, no SNM will ever leave Containment Vessel \#1.

While we expect that the experiment vessel, by itself, is sufficient to contain any SNM from the TRUMPET experiment series, it would not be unexpected if occasionally a vessel would seep. We would expect that any SNM that seeped from an experiment vessel would remain in the zero room or on the surfaces of the zero room walls.

The primary containment barrier is essentially a copy of the design used for HOLOG, BAGPIPE, CLARINET, OBOE, and PIANO. It is capable of containing HE loads considerably larger than will be used in the TRUMPET series of experiments. Because the TRUMPET experiments are in vessels, the primary containment barrier should see no shock or gas pressure during the TRUMPET experiment series. Regardless, the primary barrier has been designed to contain the TRUMPET experiments as if no shock and gas pressure mitigation is provided by the vessel. We fully expect that no SNM will be released into the diagnostics rooms outside the primary containment barrier.

The secondary containment barrier in the U1a.100 drift will protect the rest of the U1a Complex from contamination if the primary barrier fails to provide containment. This is extremely unlikely for the TRUMPET experiments since the primary containment barrier will see no shock or gas pressure. The secondary barrier has been designed to fully contain the HE gases and SNM debris, assuming the primary containment barrier and the experiment vessel do not exist.

The two nested containment vessels provide assurance that the LLNL TRUMPET containment objective is met and no SNM will be released to any uncontrolled environment as a result of the TRUMPET experiments. 


\section{Geology}

Mining of the U1a.102 drift started in November 1997 and was completed in February 1998. Fibercreting was applied immediately after the drift was mined. The U1a.102C drift was mined from October to December 1998. The U1a.102D drift was mined from November 1998 to January 1999. Both of these drifts were mined in two passes (an upper and lower cut) because of their height. Mining conditions were typical for the U1a complex, with some minor slabbing in the backs of the drifts. Undesirable ground conditions were mitigated by an initial coat of fibercrete applied prior to mining the lower cut.

Descriptions of the geologic setting and physical property measurements for the U1a Complex have been reported in a number of documents (Drellack et al., 1989; Allen, 1995, 1996, 1998; Huckins-Gang, 2003a, 2003b). Mapping, photography, and sampling documented the LLNL drifts and rooms as mining progressed in the U1a.102 drift and the U1a.102D alcove, the TRUMPET zero room (Allen, 1999). As shown in Figure 3, the alluvium in and around the TRUMPET zero room consists of inter-fingered lenses and layers of sands, gravels, and cobbles. The alluvium is similar to that found elsewhere in the U1a Complex, including LEDOUX, KISMET, HOLOG, REBOUND, STAGECOACH, CIMARRON, BAGPIPE, CLARINET, OBOE, and PIANO.

Figure 4 shows the location of faults in the U1a.100 drift complex near the TRUMPET zero room. Several faults were seen in the 102D alcove, near the keyway notch cut for the primary barrier, and several fractures were observed in the right rib between the faults and the U1a.102 drift. The faults are small, with less than $6 \mathrm{~cm}$ offset, narrow gouge-filled traces with poorly developed slickensides, and display little to no aperture. Fractures in the right rib of the U1a.102D drift may be structural or stress-relief features. This location is part of a north-northeast trend of faults identified in the U1a.01, U1a.100, and U1a.101 drifts. The fractures may be related to stress relief due to their location on the pillar between the U1a.102 and U1a.102D drifts. Stress relief fractures like these have been noted elsewhere in the U1a Complex. The faults and fractures are similar to previously mapped features seen in the U1a.100 and U1a.102 drifts. All of these features are consistent with the structural trends of faults and fractures measured elsewhere in the U1a Complex (Figure 5).

Permeability of the alluvium has been measured in several places in the U1a Complex. The typical values are 1-5 darcies. Because the faults and fractures are intrinsically filled, and then covered with fibercrete, we don't expect them to form preferential pathway for gas transport. We have witnessed faults in other experiment alcoves in U1a (HOLOG, BAGPIPE, OBOE, and PIANO) with no observable effect on gas transport. We expect the permeability of the TRUMPET zero room will be similar to that of HOLOG, BAGPIPE, CLARINET, OBOE, and PIANO, based on similarity in the geology and on results of pressure tests on the primary barrier. 


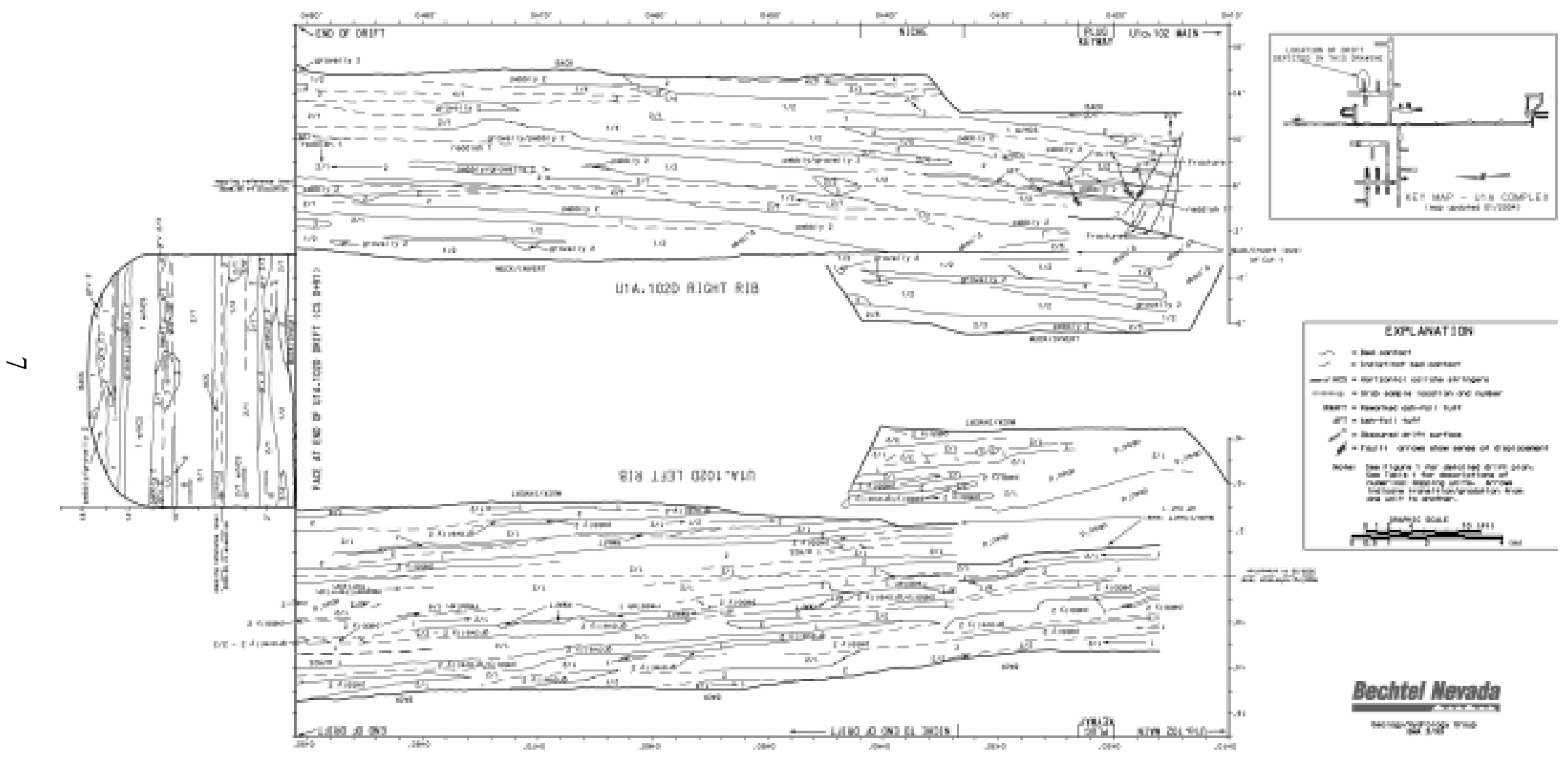

Figure 3. Geology of the U1a.102D drift. 


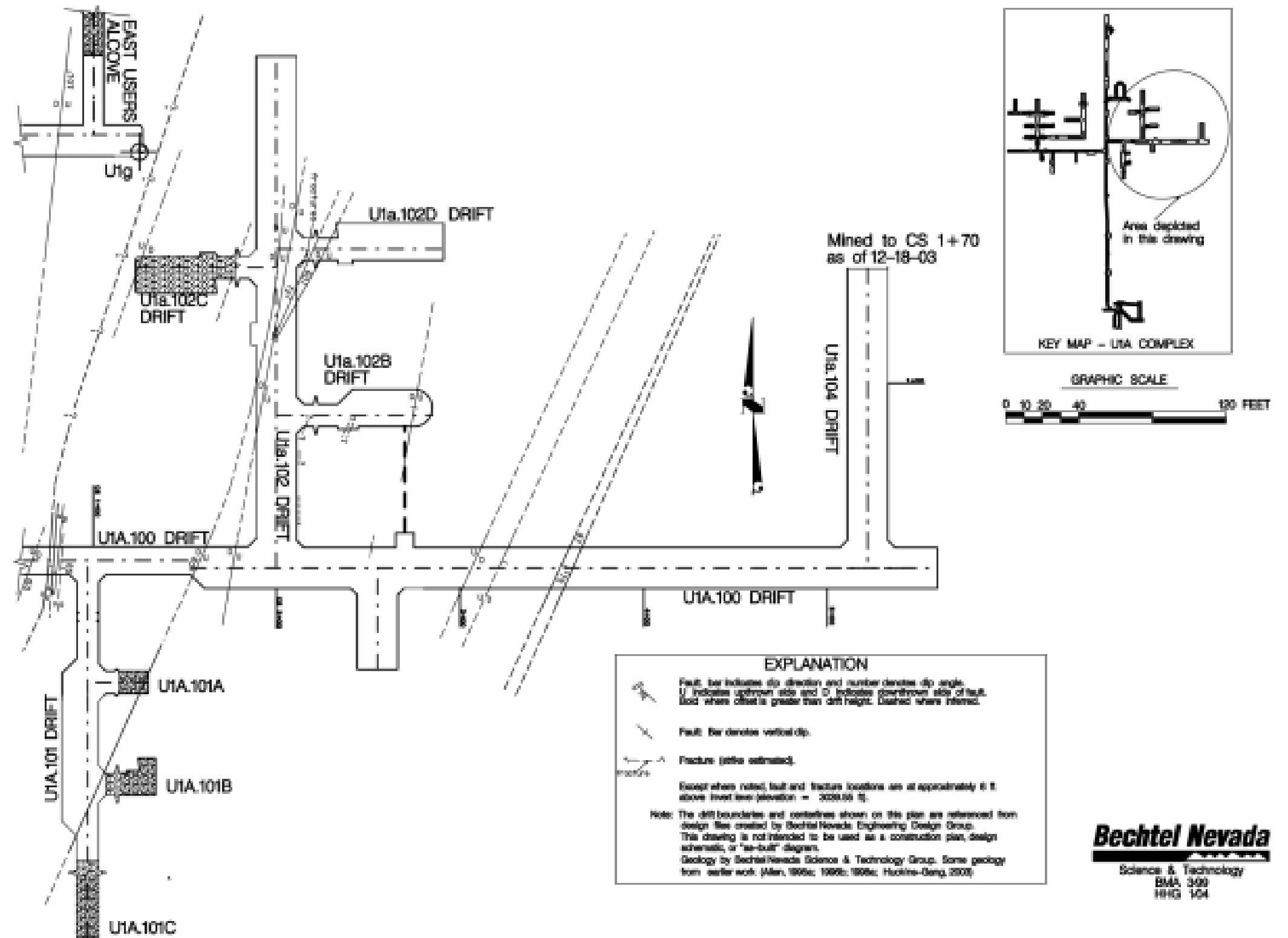

Figure 4. Location of faults and fractures in the U1a.100 portion of the U1a Complex. 


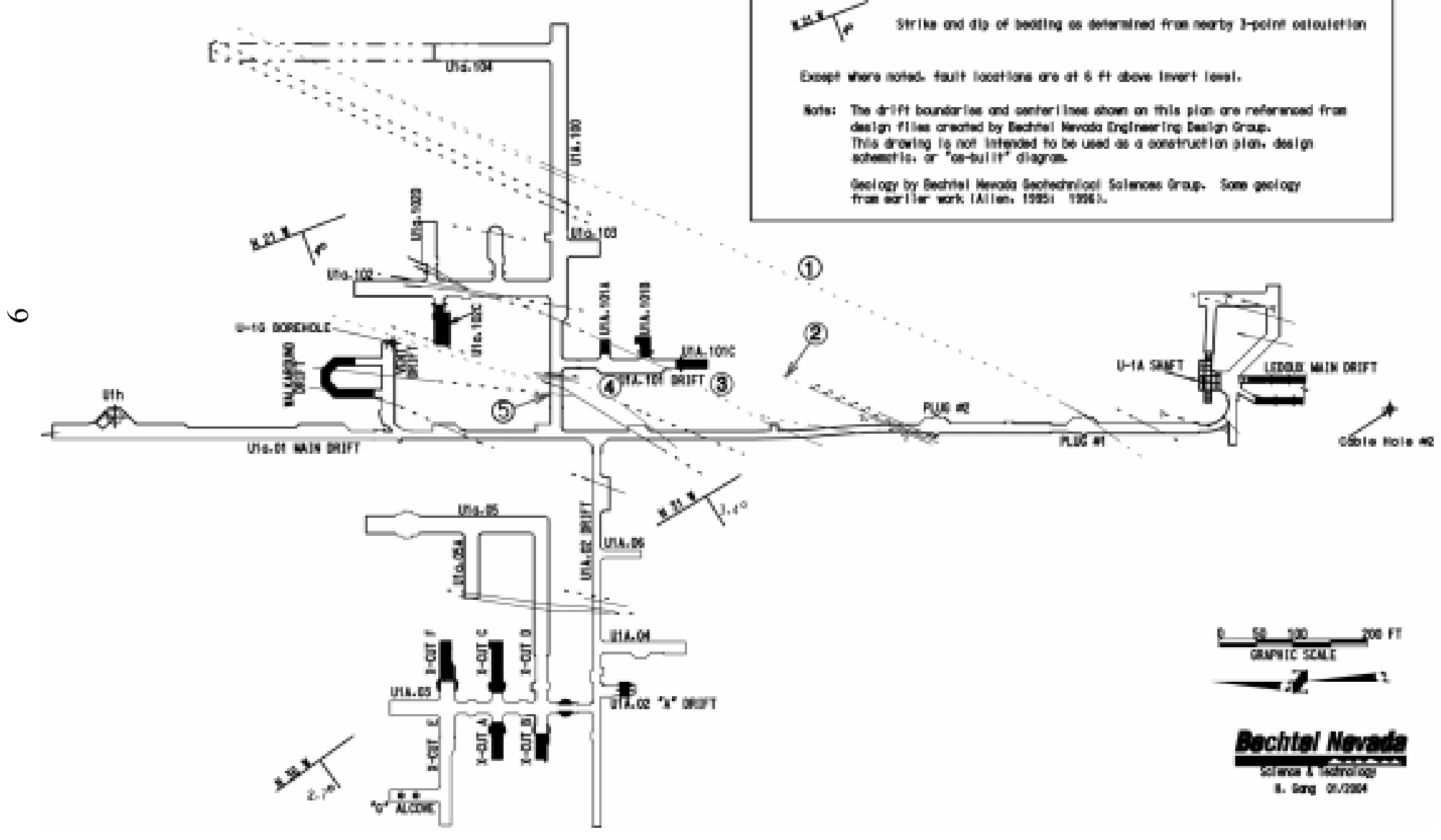

Figure 5. Faults and fractures in the U1a Complex. 


\section{Experiment Vessel}

The TRUMPET experiment series will use experiment vessels. The vessel will be placed in the zero room during experiment setup and the experiment package will be sealed in the experiment vessel. After the experiment has been executed, the experiment vessel will be moved to the rear of the U1a.102D alcove and entombed in grout. The vessel containing an expended experiment will never leave the zero room. The TRUMPET alcove was designed with sufficient space to entomb 20 experiment vessels. The use of the experiment vessel and entombment for the TRUMPET experiments is identical to that utilized for the OBOE series of experiments.

The vessels to be used for the TRUMPET experiments will be the same as those designed, tested, and used for the OBOE experiments (Figure 6). Appendix A contains a selection of engineering drawings for the vessels. The vessels are constructed of API-5L pipe with machined A572 steel plate top, bottom, and flanges that are welded onto the pipe section. All steel is 50-ksi material. The pipe section has a wall thickness of 1.25 inches, which is the minimum wall thickness of the vessel. The vessels will be about 42 inches tall and 36 inches in diameter. Penetrations in the vessels are the lid; fiber optic, electrical, and detonator cable feedthroughs; and ports for laser illumination and holography output. The various penetrations are standardized and will be closed with different types of fixtures that bolt to flanges on the vessels at the penetrations. Each fixture will be sealed to a flange with a double O-ring assembly. The type of fixture bolted to a specific flange will depend on the diagnostic requirements and the experimental setup within each vessel.

When originally designed for the OBOE experiments, specific concerns on vessel performance included leakage at penetrations and cable feed-throughs, O-ring sealing on glass windows, and window survivability. The DYNA code was used to simulate shock dynamics on proposed designs, and indicated that the lids of the vessels are the limiting factor in the design steel vessels. Static tests with all penetrations blanked off suggest that the yield pressure of the lid, using 50-ksi material, would be about 850 psi. Dynamic tests using C4 explosive (at energies equivalent to various LX-14 weights), 1- and 2-inch-thick glass windows, and evacuated vessels indicated that no leaks were present past the first O-rings and glass windows survived using HE weights up to 100 grams. This is within the maximum HE weight limit for the TRUMPET experiments. Interstitial leaks past the first O-ring occurred at a HE weight of 227 grams, and all windows survived. At a HE weight of 454 grams, there were interstitial leaks past the first O-ring, a possible breach of the lid, broken 1-inch glass windows (both inner and outer), and broken 2-inch glass inner windows. The OBOE experiments, designed with a maximum HE weight of 65 grams, showed that experiment vessels confined and contained all SNM.

As on the OBOE experiments, several factors will be applied to mitigate the effects of blast and shrapnel within the vessels for the TRUMPET experiments. Vacuum within the vessel provides a 2-to-3-times reduction in stress. Blast shields will be used on feed-throughs. Aluminum honeycomb will be used over optical ports for energy sorption as required.

The design and testing of the experiment vessels and the results from the OBOE experiments indicate that the vessels will perform as confinement vessels as planned for the 
TRUMPET experiments limited to a maximum HE weight of 85 grams. In fact, the vessels will probably contain each TRUMPET experiment. However, given the uncertainty in predicting the effects of shocks and the actual distribution of shrapnel in small confined spaces, it would not be unexpected if there was a small seep from a vessel during one of the TRUMPET experiments.

Due to this uncertainty, we have not designated the experiment vessel as Containment Vessel \#1. However, we have total confidence that the experiment vessel will not dynamically fail. The experiment vessel will provide effective shock mitigation (at a minimum) and will probably contain each TRUMPET experiment.

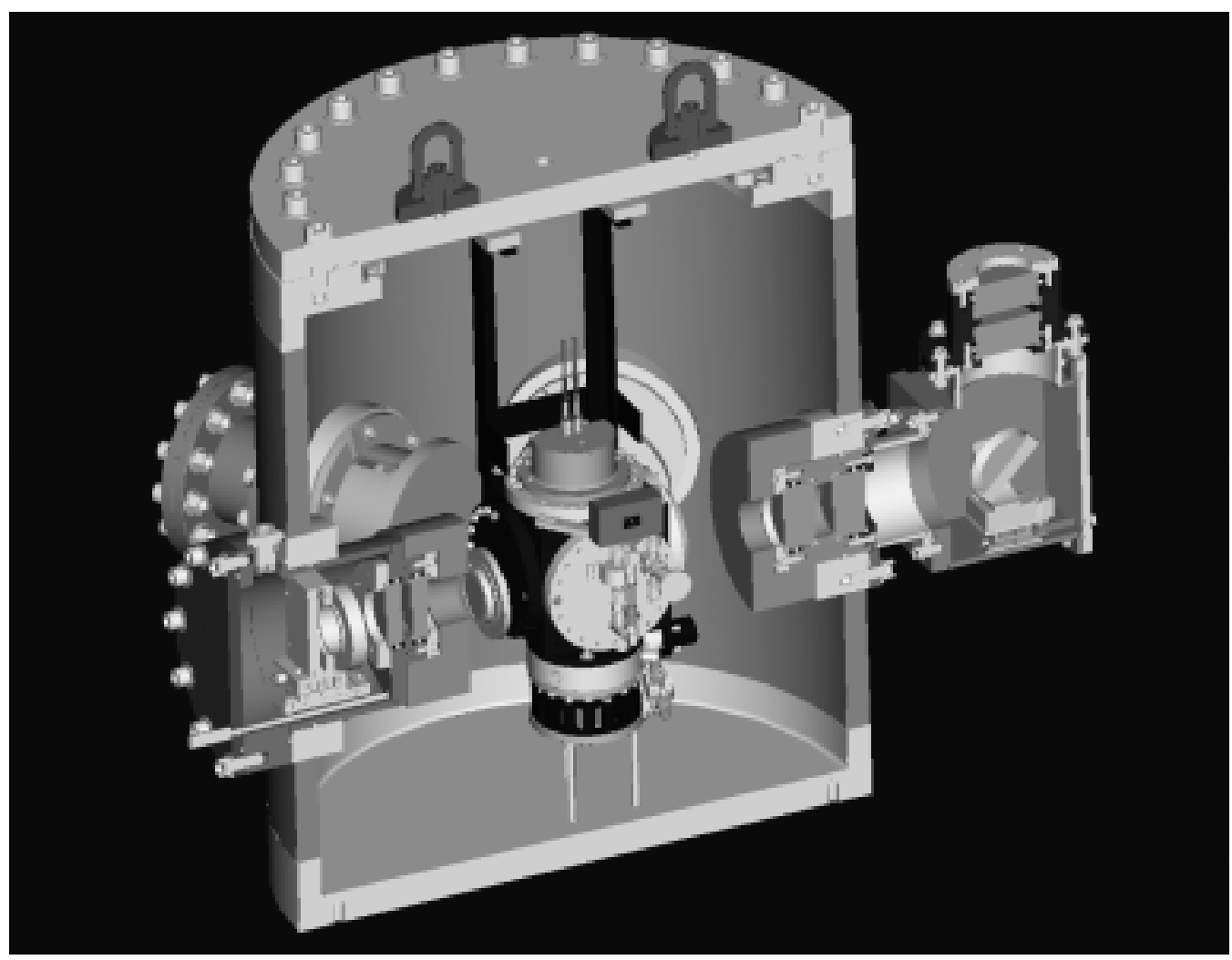

Figure 6. Schematic of an experiment vessel showing penetrations and flanges. 


\section{Blast and Quasi-Static Gas Pressures}

The volume of the experiment vessel (approximately 20 cubic feet) mitigates all blast pressure from each TRUMPET experiment at the defined maximum HE weight of 85 grams. Thus, the primary containment barrier will see no blast pressure. Experience with OBOE experiments in identical vessels, although at a slightly lower explosive weight limit, gives us confidence the vessels will provide confinement as designed.

We expect that the vessel will contain any quasi-static gas pressure produced by the HE detonation products. The vessel will be evacuated during each TRUMPET experiment. The BLASTX code, Version 4.2 (Britt and Lumsden, 1998) was used to estimate the quasi-static gas pressure in the vessel. Results indicate that following an initial short-lived shock from the experiments, a quasi-static gas pressure of about 30 psia will be formed. The pressure will rapidly decrease due to thermal conduction and within 0.5 second will become subatmospheric. In about 2.5 seconds the gas pressure in the vessel will have fallen to less than 2 psia.

A complete failure of the experiment vessel would result in a slight reduction of the ambient pressure in the zero room behind the primary containment barrier after 0.5 seconds. Air would be drawn out of the alluvium surrounding the zero room through the filter-covered wall on the face of the zero room.

As configured, the TRUMPET experiments cannot produce any positive quasi-static pressure on the secondary containment barrier. If both the experiment vessel and primary containment barrier failed, a slight negative pressure could be produced at the secondary containment barrier. Again, air would be drawn in from the alluvium surrounding the drifts to eliminate this negative pressure.

It is essentially impossible for the TRUMPET experiments to produce a positive quasistatic pressure on either containment barrier. 


\section{Primary Containment Barrier}

The TRUMPET primary containment barrier is a structure in the U1a.102D drift that seals the drift and forms the zero room. The zero room volume is approximately 20,731 cubic feet. The drift volume behind this barrier plus the surrounding alluvium form Containment Vessel \#1. This barrier is a duplicate of the primary barriers used for BAGPIPE, CLARINET, OBOE, and PIANO experiments with only a few minor modifications. The barrier was designed to contain an open experiment (an experiment not in a vessel) expected to occur after the TRUMPET experiments are completed. As constructed, the primary barrier is drastically overbuilt for the TRUMPET experiments in vessels.

The TRUMPET primary containment barrier was constructed from steel I beams, 1-inch steel plate, and fibercrete. The barrier was firmly attached to the drift walls by a grout keyway and to a steel pedestal captured by grout under the drift invert. The drift invert was then covered with six inches of concrete. Penetrations through the barrier include a 42-inch ID manway crawl tube, six 16.38-inch optical LOS pipes, and one air line/grout tube. There are no other penetrations through the barrier. The main engineering drawings for the primary barrier are included in Appendix B.

The barrier is attached to the alluvium via a grout keyway that securely fastens the barrier to the formation. A 2.5-foot-wide steel channel (part of which is formed by the 1-inch steel plate) was secured by rock bolts to the formation behind the keyway. The keyway extends approximately 2.5 feet into the formation at its sides and is approximately 4 feet deep. Grouting of the keyway was closely monitored to ensure the grout ring was completely filled. The grout ring was "topped off" by pressure grouting after about one month. Pressure grouting should fill any voids in the alluvium or voids that may have formed between the grout ring and alluvium. That being the case, the minimum path length through the alluvium around the primary containment barrier exceeds eight feet. The presence of tight faults mapped near the keyway does not compromise this minimum path length. The mapped fractures (possible stress relief features in the pillar due to mining) are located on the portal side of the keyway and will not compromise the minimum path length identified around the keyway.

All seams in the 1-inch steel plate are gas-seal-welded. The manway, optical LOS penetrations, and the airway/grout penetration are structurally welded to the steel plate. The steel plate was spot-welded to the I-beam structure on the diagnostics side of the primary barrier. All welds passed inspection. The pressure integrity of the primary barrier was tested multiple times during construction by overpressurizing the zero room to 2 psig. Any leaks in the welds discovered during the pressurization test were rewelded and then retested.

The 42-inch manway used for TRUMPET experiments will be secured prior to detonation using two Class 75-TB closures, as was done for OBOE and PIANO. These closures are rated for $175 \mathrm{psig}$ at $250 \mathrm{~K}$. The manway with two closures was built as a unit by the manufacturer, with the inner closure designed to be closed from the inside of the tube with cleats and bolts. We will follow the bolting procedure put into place for OBOE 5, which reduced the number of bolts closing the manway from 16 (maximum) to four. The manufacturer has told us that the manway will hold 25 psi with only four bolts installed on each door. However, they will 
not provide a written manufacturer's rating for this. The four symmetrical bolt locations will be identified to ensure they are the same locations used during final button-up as those used for pressure testing.

Using four instead of 16 bolts saves time on the button-up and reentry procedures on an already long shot-day schedule, and we believe it does not compromise containment features for the TRUMPET experiments. OBOE experiments in vessels resulted in perfect shock and quasistatic pressure mitigation and shrapnel confinement. All SNM was confined to the experiment vessels. Pressure data from inside the OBOE vessels indicates that the quasi-static gas pressure may not have even reached atmospheric pressure at any time during the experiments. We expect the same for TRUMPET experiments in the same vessels. Due to the size of the TRUMPET experiments, even if there was dynamic failure of a vessel, the primary barrier would see no pressure challenge. We believe the reduction from 16 bolts to four eases operation without compromising the containment plan.

There are six optical port penetrations in the primary barrier that may be used to transmit optical diagnostics data from the zero room to the diagnostics recording equipment on the portal side of the primary barrier. The penetrations are 17-inch-OD steel pipe welded to the barrier that form housings to hold window assemblies. Standardized window assemblies are then attached to flanges on the Working Point and portal sides of the barrier. The glass coatings and number of window assemblies will vary depending on experiment requirements. Details on optical window assemblies are presented later in this report. Unused window ports will have aluminum blind flanges attached on both sides of the primary barrier.

The air line/grout line was constructed of 10-inch Schedule 60 pipe. Prior to execution this line will be used as an air line. After the final experiment in U1a.102D it will be used to grout the expended alcove. As has been done since OBOE 5, the 10-inch line will be closed on the portal side of the barrier with an aluminum blind flange secured with four bolts in a symmetrical pattern. The previous blind flange assembly with 12 bolts was rated at $300 \mathrm{psi}$. The new lightweight flange secured with four bolts has a rating of about 45 psi as calculated by Bechtel Nevada engineers. This change was also put into place when the bolting pattern for the manway and unused LOS flanges was changed. The closure on the Working Point side of the barrier will continue to be a 10 -inch butterfly Victaulic valve rated at 300 psi.

All welds on the Working Point side of the steel plate were covered with GLUVIT ${ }^{\mathrm{TM}}$. This material is a waterproof epoxy sealer. It is commonly used to seal leaky rivets on aluminum and steel ships. The Gluvit ${ }^{\mathrm{TM}}$ moves with the ship hull as it vibrates and flexes and does not part from the members to which it is bonded. When used to seal steel ship hulls, a 10-mil-thick coat will withstand greater than 4000 pounds per square foot water pressure ( $28 \mathrm{psi})$.

Inside the primary barrier, fibercrete was applied in a minimum thickness of 6 inches in two 3-inch applications over the barrier, the exposed portion of the keyway, and the zero room walls. This was done before the invert grout was poured. The purpose of this was to create a fibercrete "bottle" in the zero room with the bottle opening at the face of the zero room. The open face provides a porous pathway for gas flow into the alluvium. A dense pattern of 1/2-inch- 
diameter, 5-inch-long Nelson studs were welded to the steel plate before fibercreting to help secure the fibercrete to the steel plate and prevent spalling of the fibercrete after detonation.

As a final containment measure, the portal side of the primary barrier will be covered with Versi-Foam ${ }^{\mathrm{TM}}$, which will act as a final containment barrier for plutonium particles. This foam should encapsulate any particulates that might seep from the zero room. We view the possibility of seepage as an extremely unlikely scenario since there will be essentially no quasistatic gas pressure in the zero room. However, with the amount of expensive diagnostics equipment in the diagnostics rooms, the application of Versi-Foam ${ }^{\mathrm{TM}}$ is an effective yet inexpensive additional barrier assuring containment within Vessel \#1.

The primary barrier, designed by Bechtel Nevada and LLNL structural engineers to withstand blast pressures, will not see any blast pressure from the TRUMPET experiments since they are in vessels that provide proven blast mitigation. Dynamic and static analyses have been conducted on the barrier design, including individual components of the design. These analyses were reported to the Containment Review Panel during the BAGPIPE presentation, documented in the BAGPIPE prospectus (Burkhard, 1998), and updated in the PIANO prospectus (Burkhard, 2001). From a containment point of view, structural failure of the primary barrier during the TRUMPET experiments is not a credible scenario. 


\section{Secondary Containment Barrier}

A secondary barrier was constructed in 1996 in the U1a.100 drift near the intersection with the U1a.01 main drift to serve as the secondary containment barrier for experiments in the LLNL-mined areas of U1a. It has performed as the secondary containment barrier for HOLOG, BAGPIPE, CLARINET, OBOE, and PIANO experiments. We intend to use this barrier as the secondary barrier for the TRUMPET experiments. The volume of the drifts between the primary and secondary containment barriers is approximately 410,832 cubic feet. The tunnel volume between the TRUMPET primary barrier in the U1a.102D drift and the secondary barrier in the U1a.100 drift plus the alluvium surrounding the drifts forms Containment Vessel \#2.

Details for the secondary barrier were presented in the HOLOG prospectus (Burkhard, 1996). The main engineering drawings for the barrier are included in Appendix C. No significant changes have been made to the barrier since it was constructed and used for HOLOG.

Information about the secondary barrier is summarized here and includes minor changes made at the time of OBOE 5:

- The secondary barrier was designed to withstand a static load of 7.6 psig. This design load was based upon the maximum load from a 50-1b HE experiment in the tunnel volume at that point in time. This explosive load is exceedingly large when compared with the maximum HE limit of 85 grams stated for the TRUMPET experiments. Also, additional mining to date has increased the drift volume to almost two times that used in the initial design.

- The barrier is constructed from steel I beams, 1-inch steel plate, and fibercrete. The barrier was firmly attached by a grout keyway to the drift walls and by a sill beam to the drift invert. The barrier has a large passageway to allow normal access to the U1a.100 drift complex. The center beam is a removable plate girder. Rollers have been installed on the doors for ease of operations during button-up.

- Besides the passageway identified above, penetrations through the secondary barrier include:

- A hatch for late-time man access. The hatch through the secondary barrier allows access to the U1a.100 drift complex during button-up and reentry operations. This hatch will be closed with a new gasket and RTV ${ }^{\mathrm{TM}}$ and bolted tight during button-up operations for each TRUMPET experiment.

- Two 3-inch chilled water lines for cooling diagnostics equipment. During normal operations water lines through the barrier continuously fill a large tank of chilled water in the U1a.100 drift diagnostics area. Two redundant valves (pressure-rated at $600 \mathrm{psi}$ ) in each line on the Working Point side of the barrier will be remotely closed before zero time. Water will still circulate between the tank in the U1a.100 drift and the diagnostics room between button-up and reentry. The valves closing the water lines will have uphole readouts so the status of the valves can be positively assessed at the surface before zero time. 
- A 30-inch ventilation line. At button-up a 30-inch Tube Turn ${ }^{\mathrm{TM}}$ closure will be closed.

- A 6-inch air line and a 4-inch water line for construction purposes. At button-up the air line will be disconnected and a butterfly valve will be added to the portal side and a blind flange to the Working Point side. At button-up the water line will have redundant valves on the Working Point side and a butterfly valve on the portal side.

- Four spare 4-inch pipes. These are closed with blind flanges on the Working Point side and butterfly valves on the portal side.

- Three 0.75-inch lines for gas sampling. Normal condition of these lines is closed. Button-up procedures check that two lines are remotely closed and redundant manual valves on the Working Point for the other line are closed.

- No cables pass through the secondary containment barrier. All cables pass through Vistanex boxes located in the tunnel invert on the Working Point side of the barrier. All cables are either factory gas-blocked or discretely gas-blocked in the Vistanex boxes.

We intend to operate the secondary containment barrier for the TRUMPET experiments as we did for HOLOG, BAGPIPE, CLARINET, OBOE, and PIANO. The secondary barrier will be pressure-tested before final button-up of each experiment. This pressure test has been conducted for each LLNL subcritical experiment. Occasionally, very small bubble leaks ("fish eggs") have been detected at the sill beam/grout invert interface. Liberal application of Gluvit ${ }^{\mathrm{TM}}$ has been used to seal these leaks. The leaks are believed to be caused by the heavy equipment traversing through the barrier during normal mining operations in the U1a.100 drifts. Pressure testing provides assurance that the barrier will perform as designed for the TRUMPET experiments. 


\section{Optical Port Assemblies}

There are six penetrations for optical port assemblies on the primary containment barrier. Optical port assemblies consist of housing welded to the primary barrier and window assemblies bolted to both sides of the housing. The number of window assemblies used for a TRUMPET experiment will vary depending on diagnostics requirements. During any particular TRUMPET experiment each penetration will contain either two window assemblies or two blind flanges. The TRUMPET optical port assembly design follows that used for HOLOG, BAGPIPE, CLARINET, OBOE, and PIANO. The assembly materials and procedures were presented in the HOLOG prospectus (Burkhard, 1996). The fundamental design features have been thoroughly laboratorytested and successfully fielded. A minor change was made to the housing in the barrier that the window assembly is mounted to for the OBOE experiments (and subsequent PIANO). This was done to facilitate the alignment of the window assemblies during construction. All optical port assemblies are protected from direct shrapnel impact by the experiment vessel. Figures for optical port assemblies are shown in Appendix D.

Housings were constructed from 17-inch-OD steel pipe of 1.5-inch wall thickness welded to the primary barrier. Window assemblies are bolted to the housing with 12 bolts using two Buna-N O-rings to seal the connection. Window assemblies consist of 2-inch-thick 9-inchdiameter BK-7 glass in an aluminum housing. Inside the housing the optical glass is supported by two BJG \#9 bell jar Buna-N gaskets. A Buna-N O-ring supported by two backup rings is used to complete the sealing of the optical glass in the assembly.

The window assemblies will be mounted to the housing in the primary barrier using a procedure that was written to assure the O-rings have been properly installed. Vacuum testing with helium is used to ensure positive seals. The assembly procedures follow those developed for HOLOG and include optical measurements to determine if stress concentrations have been induced in the glass during the assembly process. 


\section{Containment Vessel \#1 and \#2 Wall Treatment}

The walls of the zero room and the diagnostics room will be completely covered with a minimum of 6 inches of fibercrete. The fibercrete will be installed in two passes to minimize or eliminate cracking in the fibercrete. The fibercrete will have a minimum compressive strength of 6000 psi in 28 days.

The fibercreting is being done to help improve drift stability and to reduce the potential of dust contamination for the complicated optical diagnostics that will be fielded on the TRUMPET experiments. In the zero room, the fibercrete will be troweled to embed the steel fibers, eliminating them as both dust collectors and a safety hazard. To further reduce the possibility of dust contamination, all of the fibercreted walls will be covered with an elastomeric coating. As a byproduct of treating the walls this way to reduce dust contamination, the permeability of the fibercreted walls is reduced from the alluvial permeability of about 2 darcies to a permeability in the millidarcy range. This helps increase the effective path length for porous flow from the zero room.

A portion of the face of the zero room will not be covered with fibercrete. It will be left uncovered in order to provide a porous surface for HE gas flow from a future non-TRUMPET experiment. This will permit porous flow into the alluvium away from the primary containment barrier and reduce any residual gas pressure in the zero room. A steel stud wall will be constructed over the top portion of the face, and the wall will be covered with a treated fabric (similar to furnace filter material) to reduce dust contamination for the optical diagnostics in the zero room. 


\section{Cables and Gas Blocking}

The types and numbers of cables, gas blocking, and cable handling for the TRUMPET experiments are basically identical to those used for the OBOE experiments. No cables pass through the primary containment barrier in the U1a.102D drift or secondary containment barrier in the U1a.100 drift. All cables that exit the TRUMPET zero room pass through Vistanex boxes. Cables that exit the TRUMPET diagnostics room pass through Vistanex boxes in the tunnel invert just inside the secondary containment barrier.

There are four Vistanex boxes associated with the U1a.102D drift - two of the typical DNA design and two modified boxes for later-time cable additions. The DNA design, where cables and Vistanex are captured in the grout invert, had been successfully utilized for many years on horizontal underground nuclear tests and eliminated gas and/or particulate transport down the cables and/or cable bundle past the box. The modified boxes have conduit in place for cables to be added after invert construction, and the Vistanex is at invert level. The Vistanex boxes with cables will be filled with either Vistanex or Hot Melt, depending upon the availability of either material at the NTS at the time the boxes need filling. (Information on Hot Melt, a generic substitute for Vistanex, was presented to the CRP during the LANL CIMARRON presentation.) Vistanex is added from the Working Point side of each barrier through two fill tubes to ensure complete filling of the boxes. Fill tubes are capped. Conduits with cables in the modified boxes will be filled with Sulfaset. One modified box and a portion of another (two of six conduits in the other modified box) will not be used during the TRUMPET experiments. Both ends of the unused cable conduits will be sealed with pipe caps or rated pipe plugs. The lids of these boxes will be sealed with RTV ${ }^{\mathrm{TM}}$ applied as a sealant and gasket. These conduits will be used for a future experiment that is not part of the TRUMPET experiment series.

All cables are either factory gas-blocked or were discretely gas-blocked in the field. The cable gas-blocking techniques used on TRUMPET closely followed what was successfully utilized on HOLOG, BAGPIPE, CLARINET, OBOE, and PIANO. The discrete cable gasblocking methods follow conventional underground nuclear testing practices. This includes the use of discrete blocks on multi-conductor cables and "birdcages" on delicate fiber optical cables. All gas blocks are located in the Vistanex boxes. Cable separators were installed to physically maintain cable separation in the invert when the cables were captured by the invert concrete pour. Table 1 lists the cable inventory and the type of gas blocking utilized for cables exiting the TRUMPET zero room. 
Table 1. Cable inventory and the type of gas blocking utilized for cables exiting the TRUMPET zero room.

\begin{tabular}{|c|c|}
\hline Cable type (gas blocking) & Quantity \\
\hline RF-44 (Factory gas-blocked) & 66 \\
\hline FO-16 (Factory gas-blocked) & 1 \\
\hline MP-46 (Field gas-blocked—discrete gas blocks) & 18 \\
\hline 3 Conductor \#8 (Field gas-blocked—discrete gas blocks) & 4 \\
\hline Fiber optic cables (Field gas-blocked—3 birdcages) & 52 \\
\hline "C" cables (Field gas-blocked—pressure feed-throughs) & 34 \\
\hline Total number of cables & 175 \\
\hline
\end{tabular}




\section{Containment Discussion}

The TRUMPET series of experiments is almost identical to the OBOE series of experiments. This includes location, geologic setting, use of experiment vessels, primary and secondary barriers design and construction, optical port assemblies, wall treatments, and cables and gas-blocking. The TRUMPET experiments have a slightly higher maximum HE weight limit than the OBOE experiments. The TRUMPET containment plan with two nested containment vessels is identical to OBOE and all past LLNL subcritical experiments.

The containment goal is to keep the SNM from the TRUMPET experiments contained within Containment Vessel \#1, which is the zero room behind the primary barrier and the alluvium surrounding it. The plutonium will be melted and blown up inside the experiment vessel. The molten plutonium will react with the high explosive gases, producing a solid-phase plutonium aerosol and particulates. Within about 0.5 seconds, the gas pressure inside the experiment vessel will be subatmospheric $(<\sim 14$ psia). Based on OBOE experience, we expect that the SNM will be fully contained within the experiment vessel. However, it would not be unexpected if a vessel in the TRUMPET series seeped. Excluding a dynamic failure of an experiment vessel, there is no threat from pressure-driven flow from a TRUMPET experiment.

The TRUMPET plan is conservative. HE weight limits for TRUMPET experiments are relatively low. These limits are similar to the OBOE experiments, and less than CLARINET and PIANO. In addition, each TRUMPET experiment will be executed in an experiment vessel that, at a minimum, will provide shock and quasi-static gas pressure mitigation. For most (and maybe all) TRUMPET experiments, the vessel will fully contain the SNM from the experiment. Each TRUMPET experiment uses two containment barriers. Precluding a dynamic failure of the welltested vessels, there will be no pressure challenge to the primary or the secondary containment barrier.

Containment for each experiment in the TRUMPET series is essentially over in seconds or minutes after the experiment. If an experiment vessel seeps, an operational decision will be made as to whether to reuse the TRUMPET alcove for another experiment. Reentry into a contaminated zero room will be conducted according to established operational procedures. Instrumentation in the zero room will help determine whether an experiment vessel seeped before reentry begins. However, all reentry activities will be conducted as though the vessel seeped. The experiment alcove will be thoroughly examined before the resumption of normal activity.

After reviewing information for the TRUMPET experiments, we conclude that the transport of SNM outside Containment Vessel \#1 is not a credible threat. Because the TRUMPET experiments are almost identical to the recently conducted and successfully contained OBOE experiments, we have high confidence in our conclusion. We believe there are redundancies in the design of Containment Vessel \#1 that will prevent any SNM from reaching the diagnostics room. We fully expect that the LLNL containment goal of keeping the SNM contained within Containment Vessel \#1 will be completely achieved. 


\section{References}

Allen, B.M. (1995), Preliminary Geologic Site Characterization of the LYNER Horizontal Drift Complex, Yucca Flat, Nevada Test Site, Raytheon Services Nevada Geologic Report, TSP:DGP:080:95.

Allen, B.M. (1996), "Preliminary Geologic Site Characterization of the LYNER U1a.100 and U1a.101 Drifts, Yucca Flat, Nevada Test Site,” Reference Letter F150-BMA-96-032.

Allen, B.M. (1998), "Update of Geology in U1a.101B and U1a.101C Alcoves, U1a Complex," Bechtel Nevada, Las Vegas, Memorandum 2150-HB-98-0028.

Allen, B.M. (1999), “Geology in U1A.102C and U1a.102D Drifts, U1a Complex,” Bechtel Nevada, Las Vegas, Memorandum 2150-HB-99-0040.

Britt, JR. and M.G. Lumsden (1998), BLASTX Version 4.0-A User's Manual for the BLASTZ Code, Version 4.0, U.S.A.E Waterways Experiment Station.

Burkhard, Norman R. (1996), Containment Prospectus for the HOLOG Experiment, Lawrence Livermore National Laboratory, Livermore, CA, CP96-02.

Burkhard, Norman R. (1997), Changes to the Containment Plan for the HOLOG Experiment, Revision 1, Lawrence Livermore National Laboratory, Livermore, CA, CP97-01.

Burkhard, Norman R. (1998), Containment Prospectus for the BAGPIPE Experiment, Lawrence Livermore National Laboratory, Livermore, CA, CP98-01.

Burkhard, Norman R. (1998), Containment Prospectus for the CLARINET Experiment, Lawrence Livermore National Laboratory, Livermore, CA, CP98-02.

Burkhard, Norman R. (1999), Containment Prospectus for the OBOE Experiments, Lawrence Livermore National Laboratory, Livermore, CA, UCRL-ID-134378.

Burkhard, Norman R. (2001), Containment Prospectus for the PIANO Experiment, Lawrence Livermore National Laboratory, Livermore, CA, UCRL-ID-143298.

Drellack, S.L., P.H. Thompson, and C.J. Rayburn (1989), Geology of the U-1a.01 Horizontal Drift Complex, Southwestern Yucca Flat, Nevada Test Site, Fenix \& Scisson, Inc., Mercury, NV, Geologic Report DOE/NV/10322-37.

Huckins-Gang, H.E. (2003a), Geology of the Ula.102b Alcove, Ula Complex, Bechtel Nevada Geotechnical Services, Las Vegas, NV, B502-MT-03-0010.

Huckins-Gang, H.E. (2003b), Predicted Geologic Conditions in the Proposed Ula.104 Drift Extension, Bechtel Nevada, Las Vegas, NV, B502-MT-03-0014. 
INTENTIONALLY LEFT BLANK 
Appendix A:

Experiment Vessel Drawings 
INTENTIONALLY LEFT BLANK 


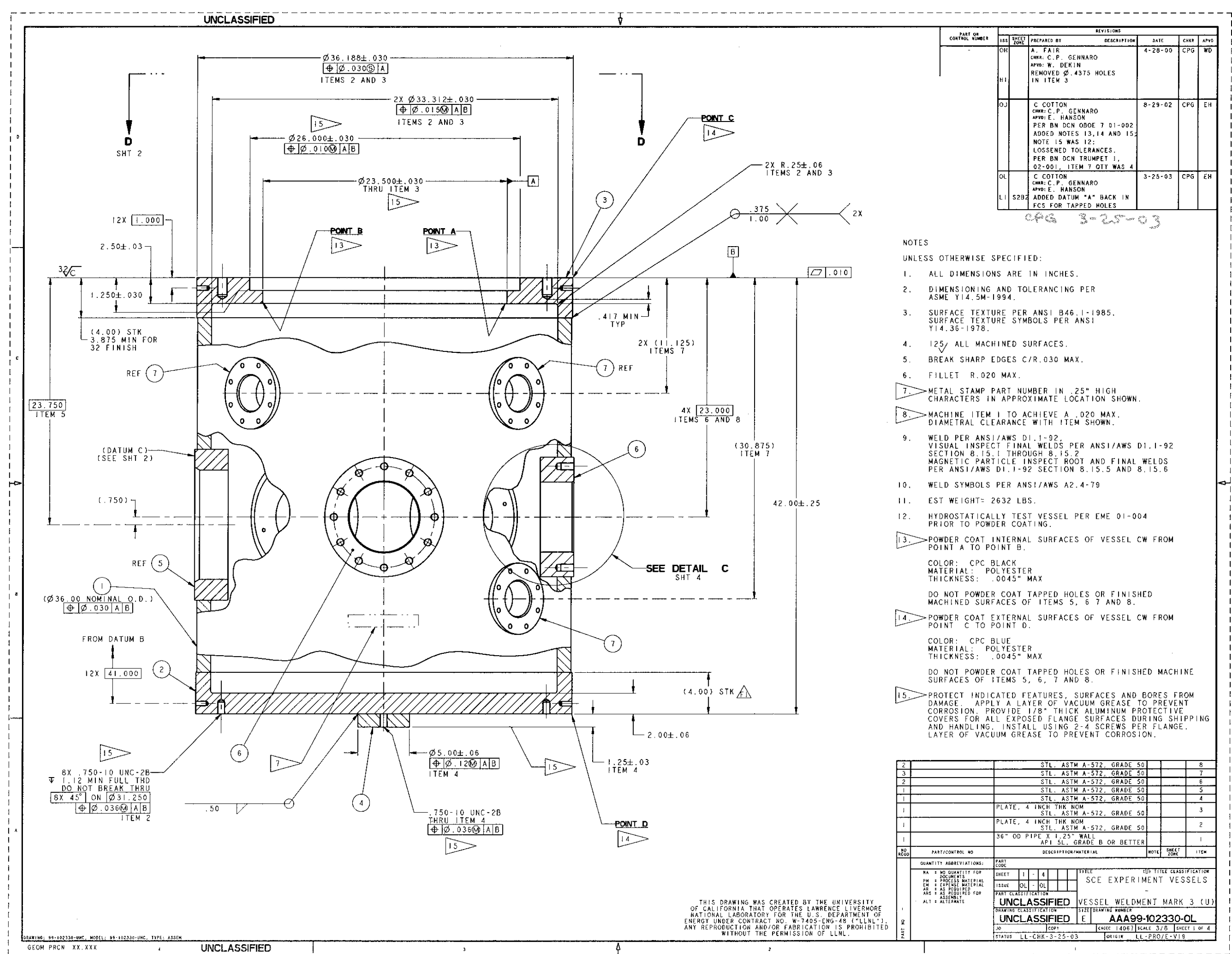




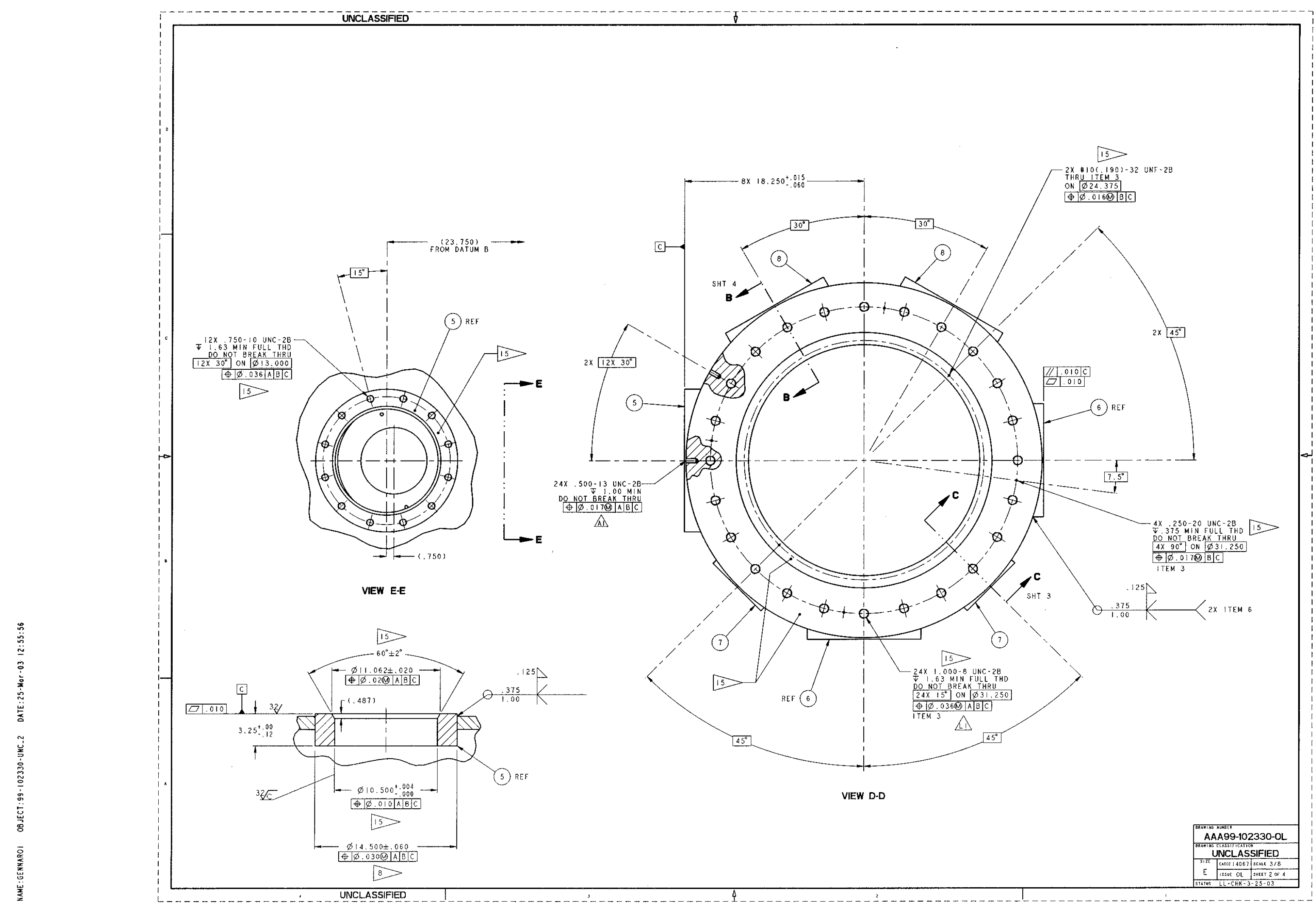




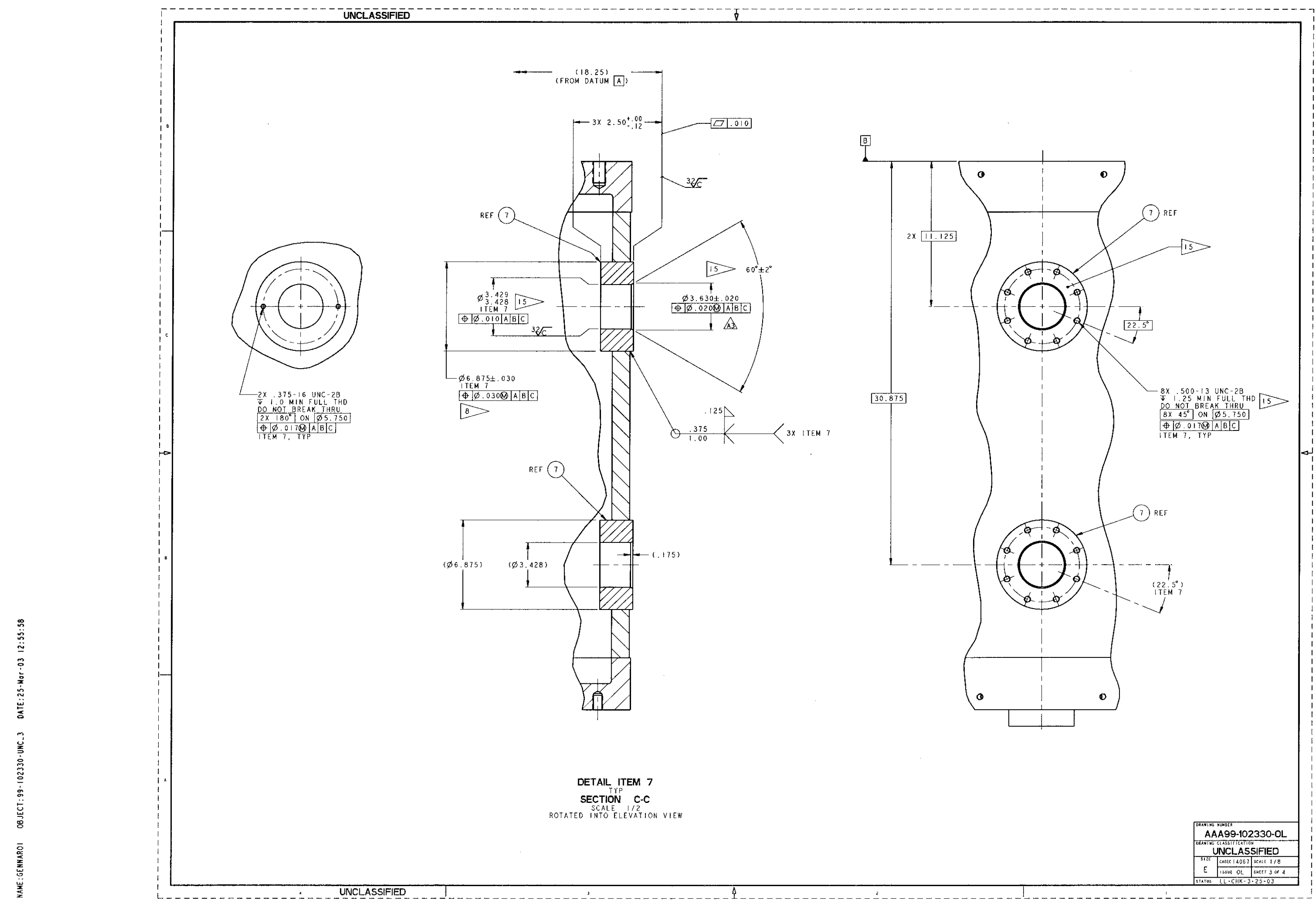

31-32 


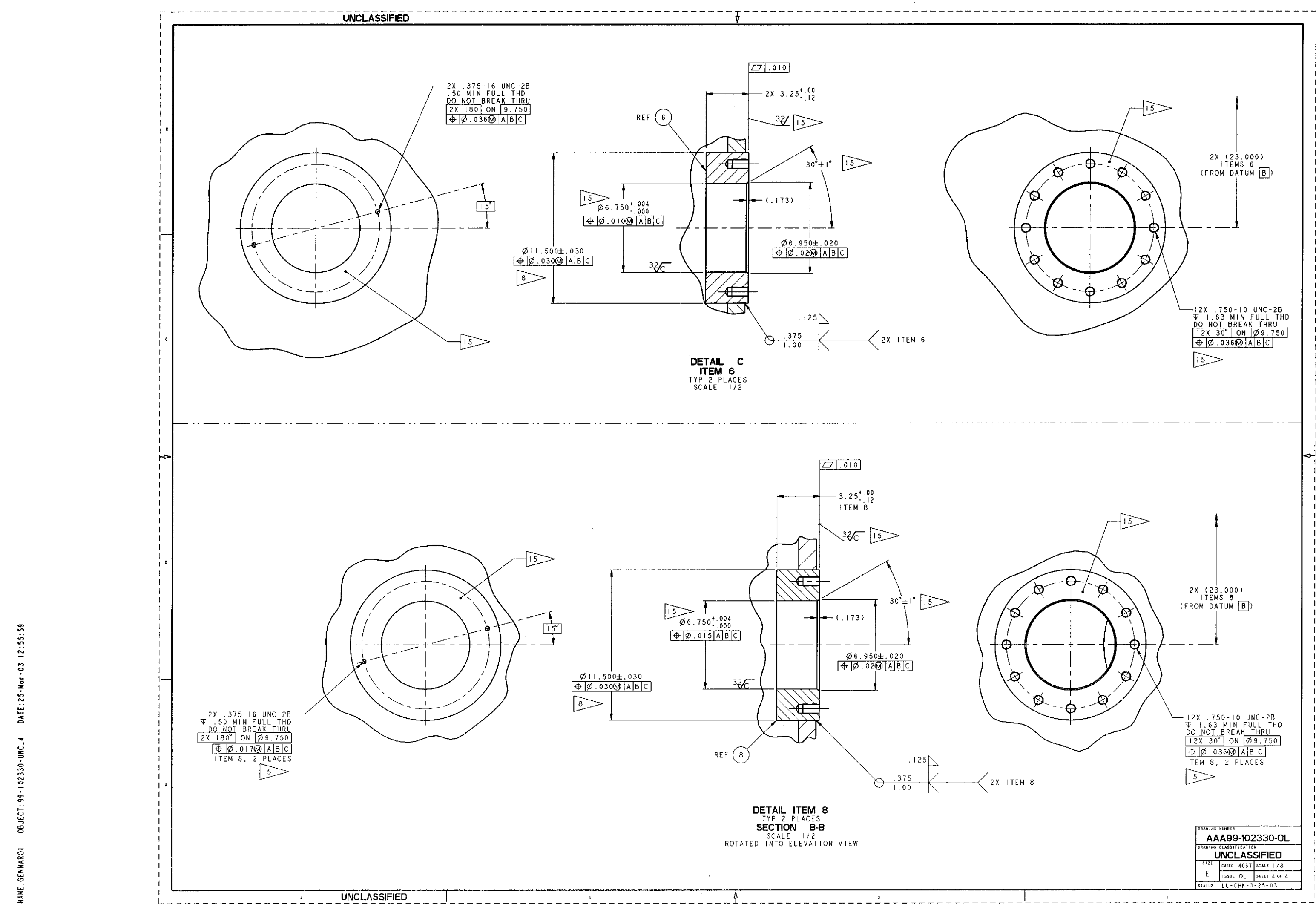




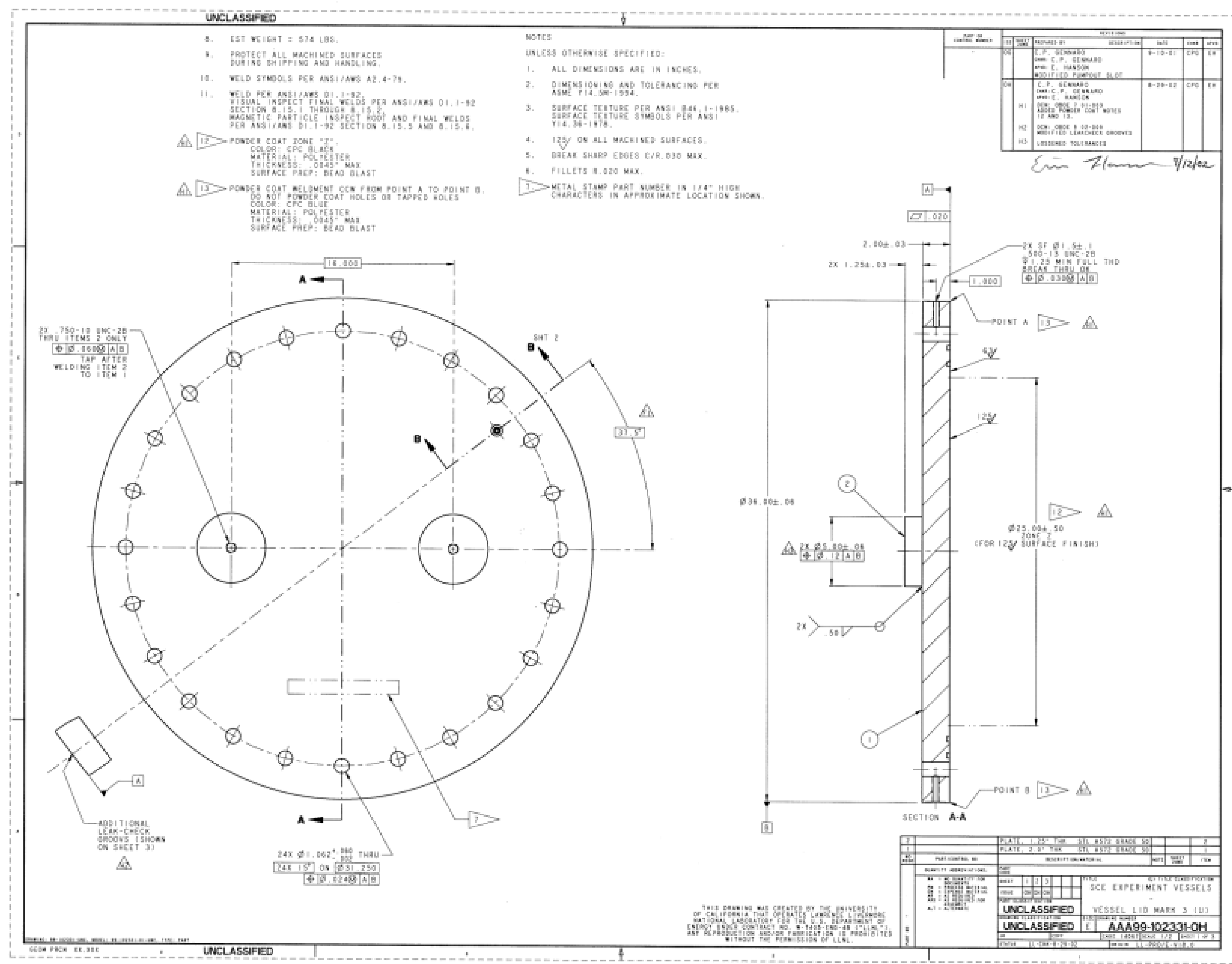

35-36 


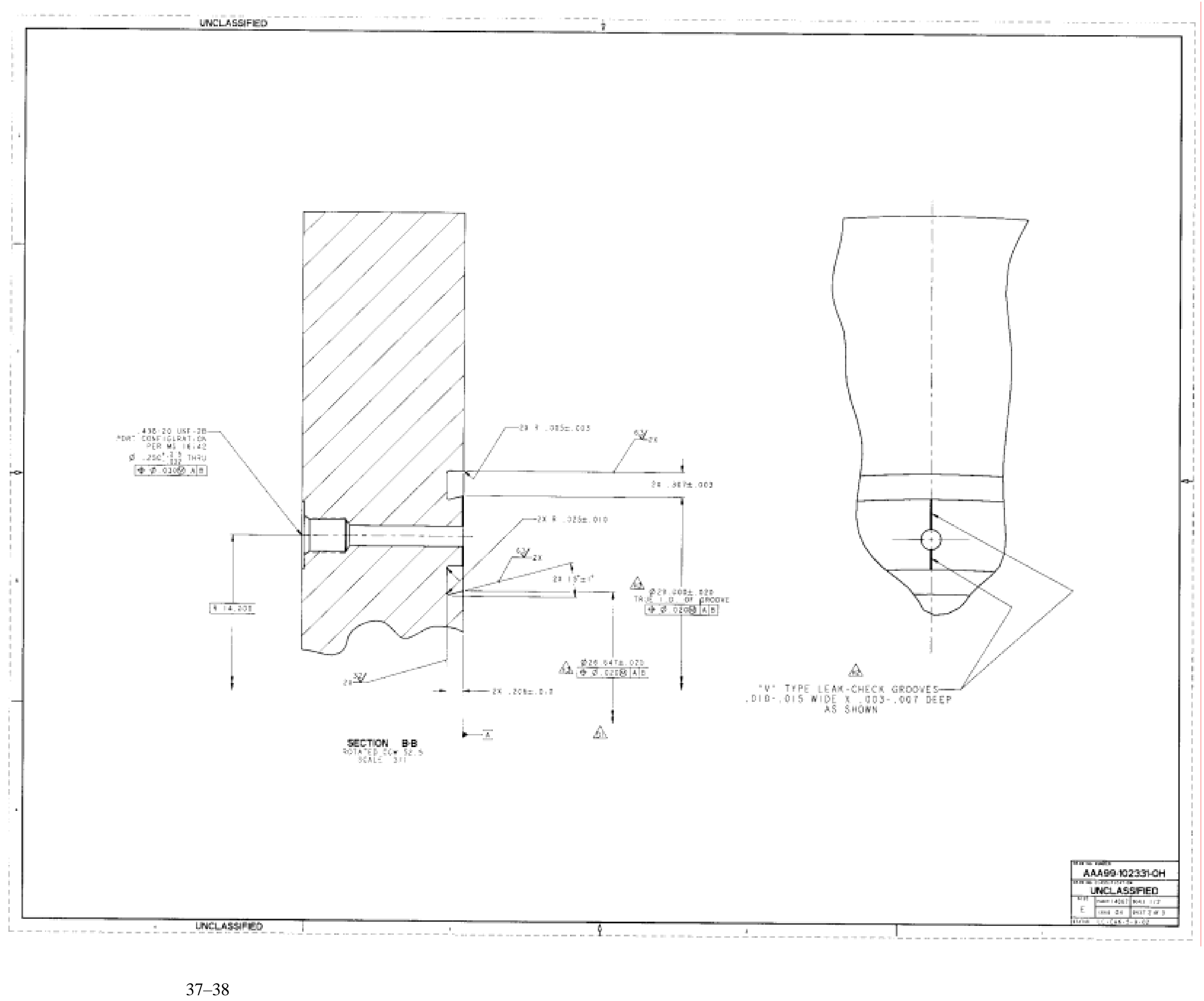




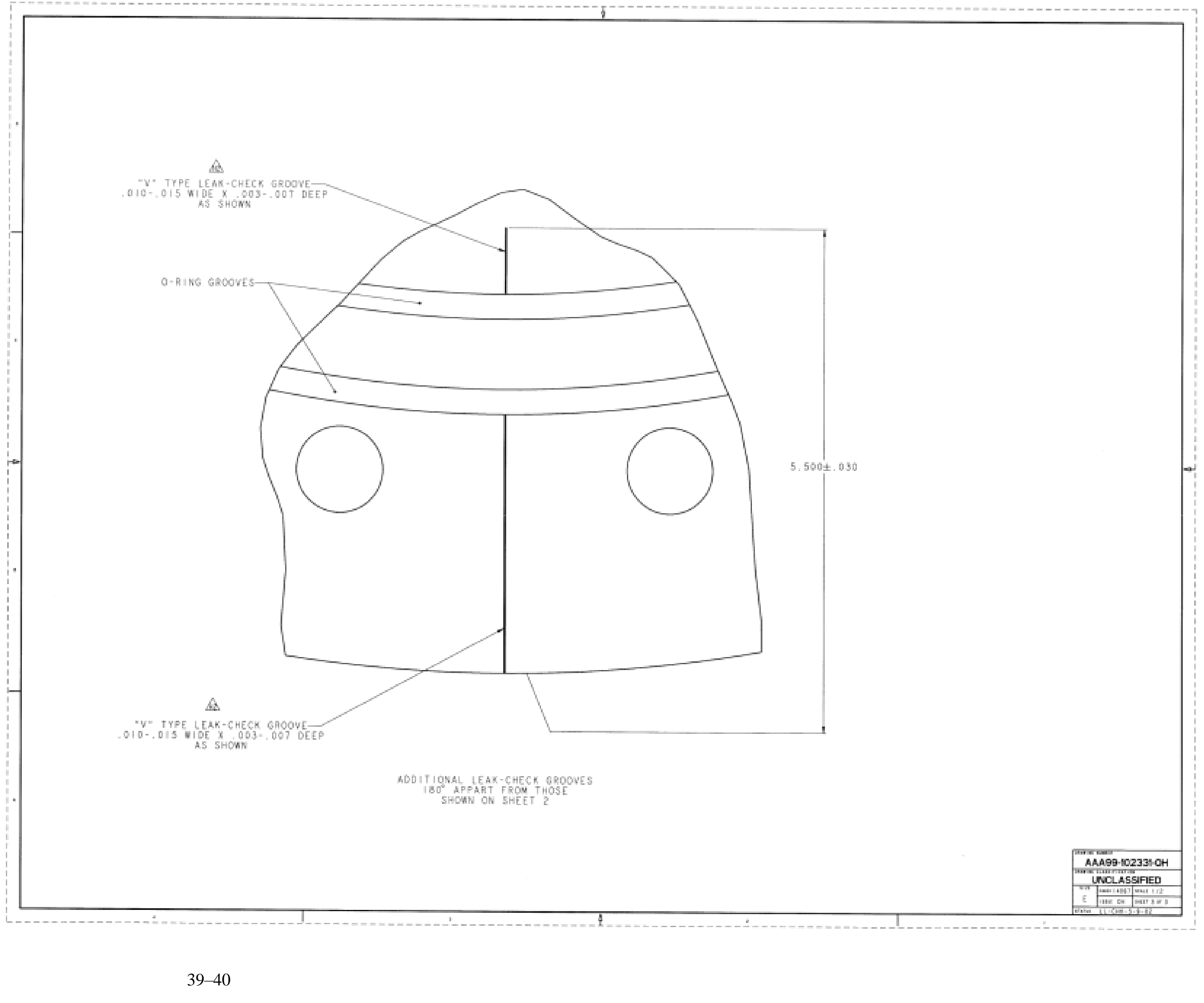


Appendix B:

Primary Containment Barrier Drawings 
INTENTIONALLY LEFT BLANK 


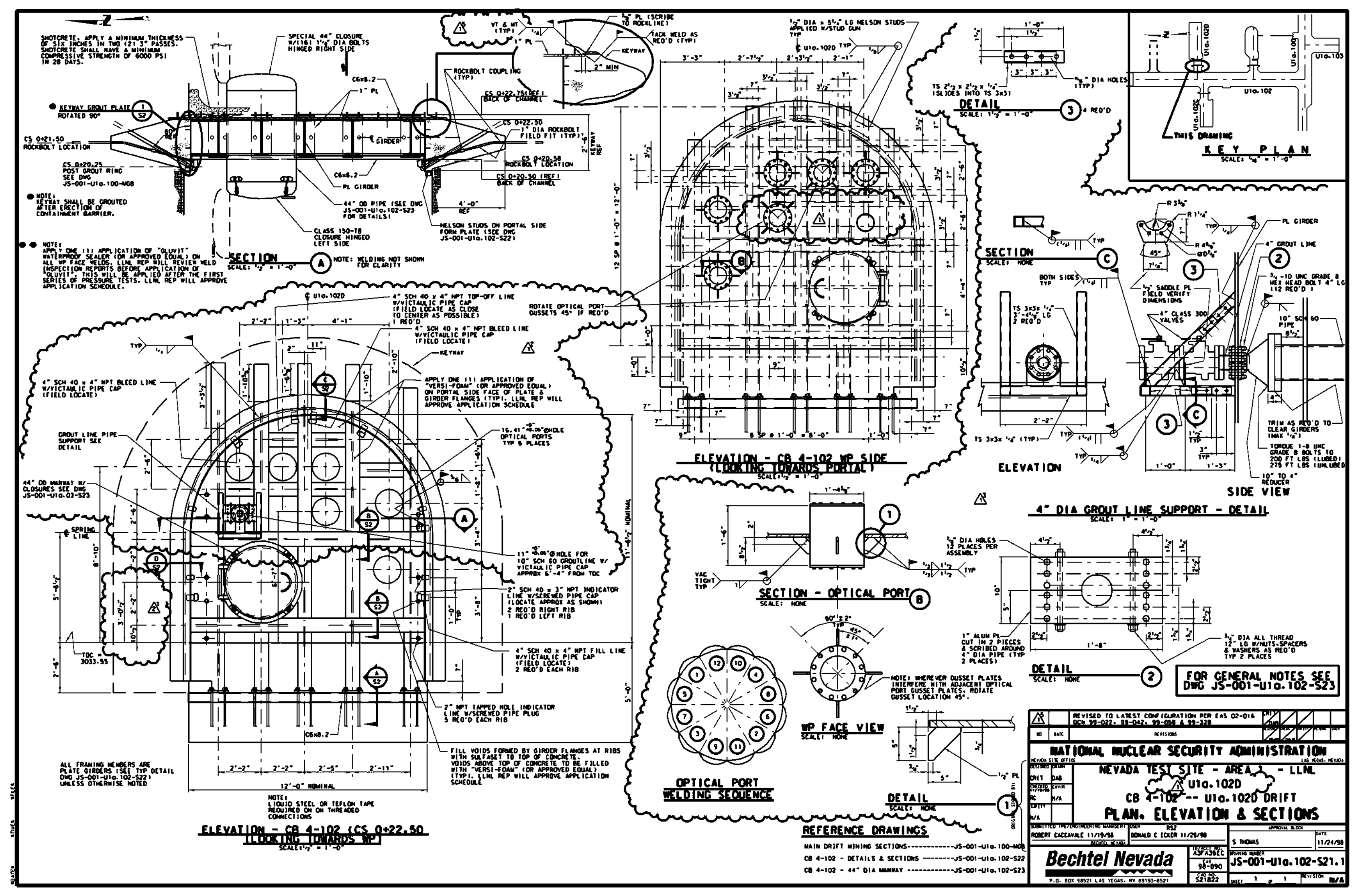




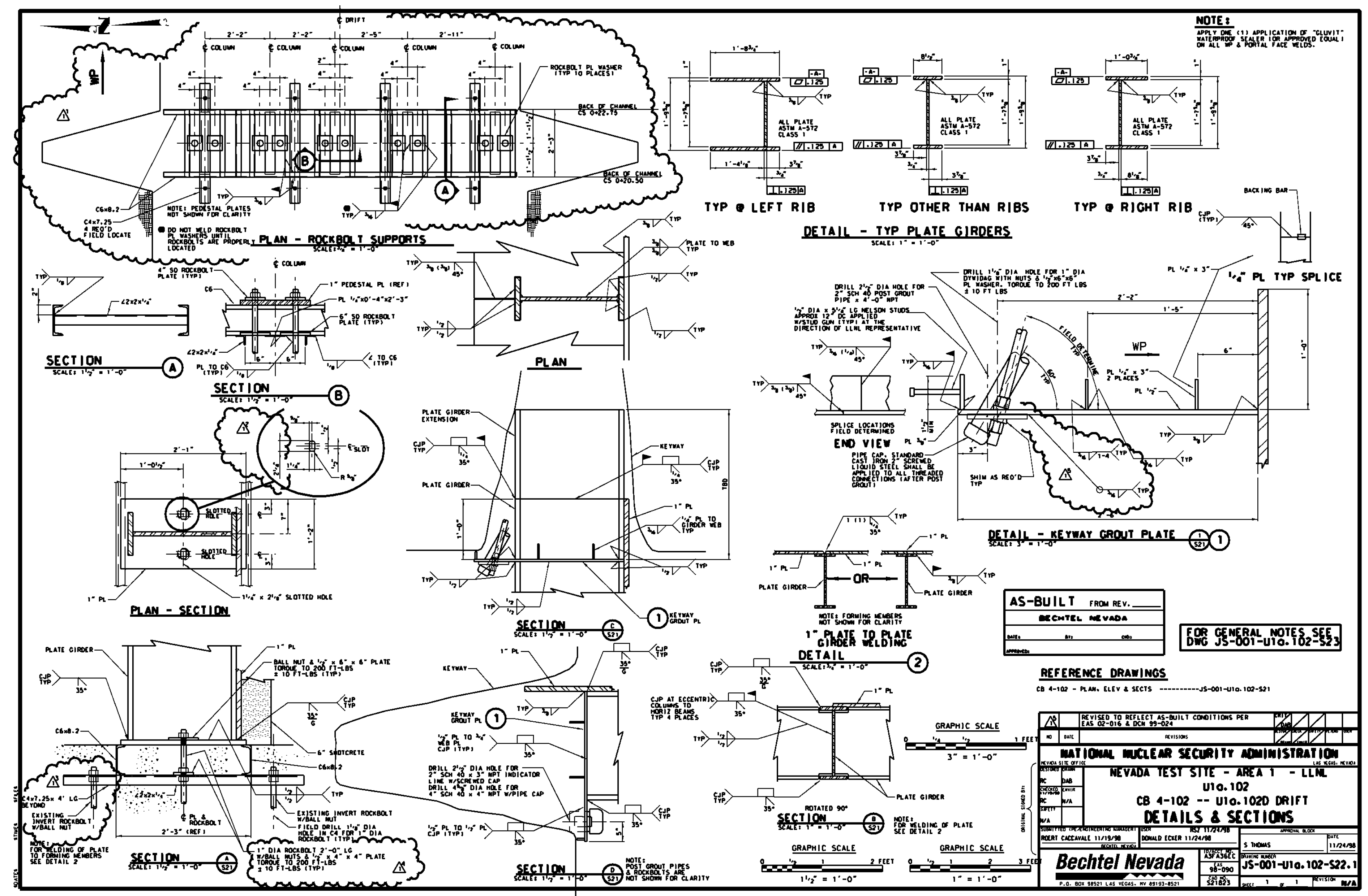




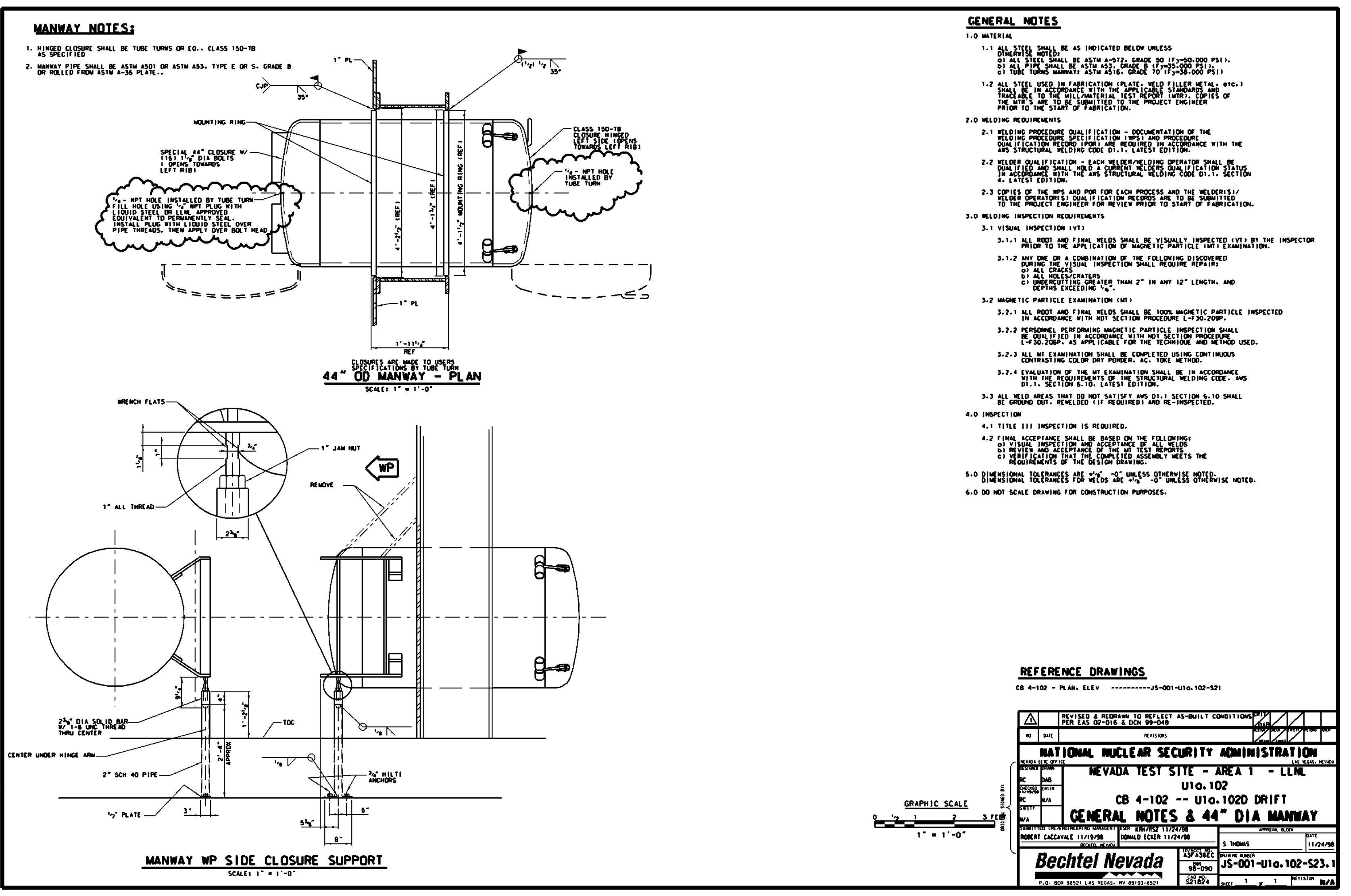




\section{Appendix C:}

Secondary Containment Barrier Drawings 
INTENTIONALLY LEFT BLANK 


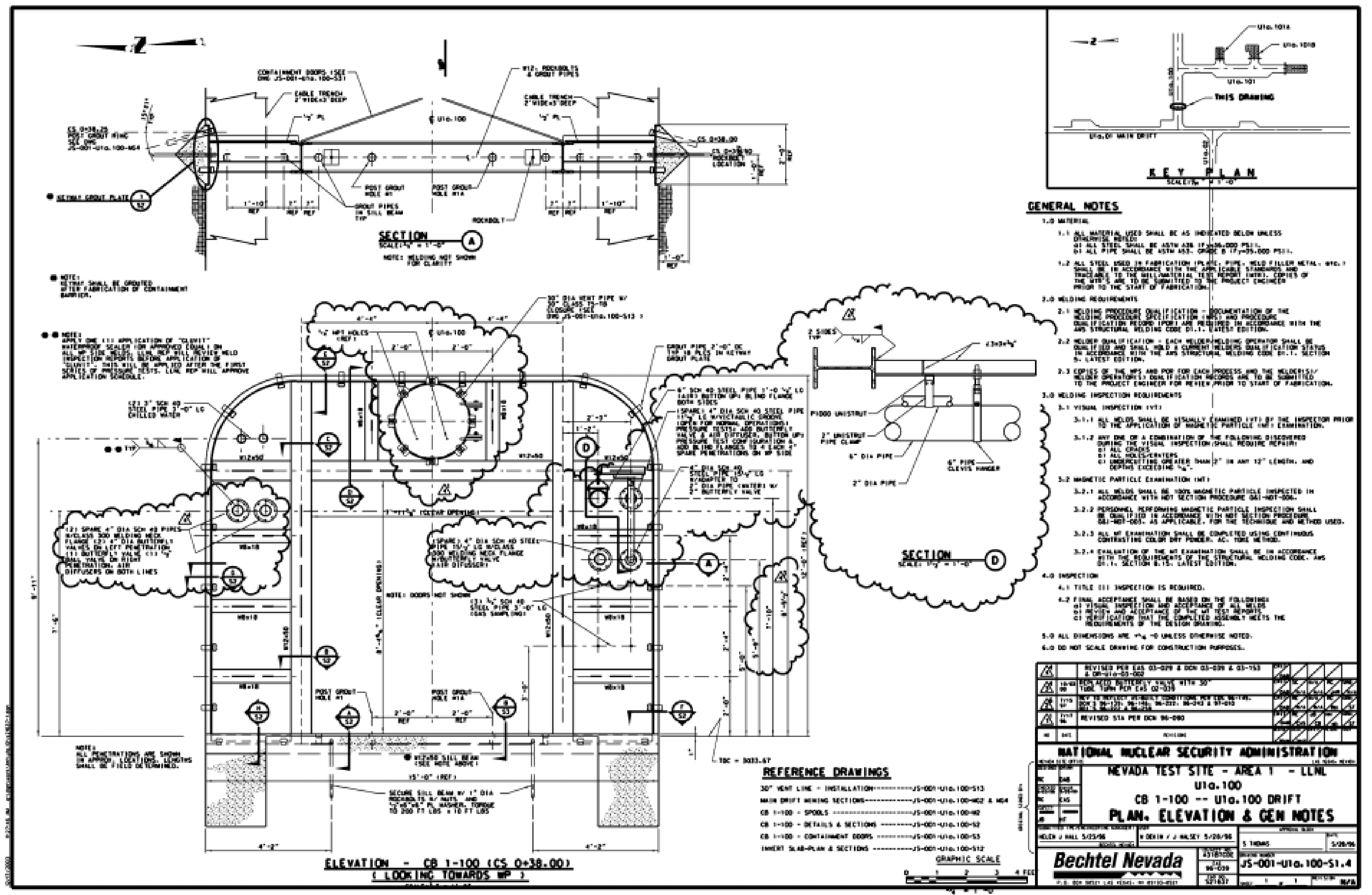




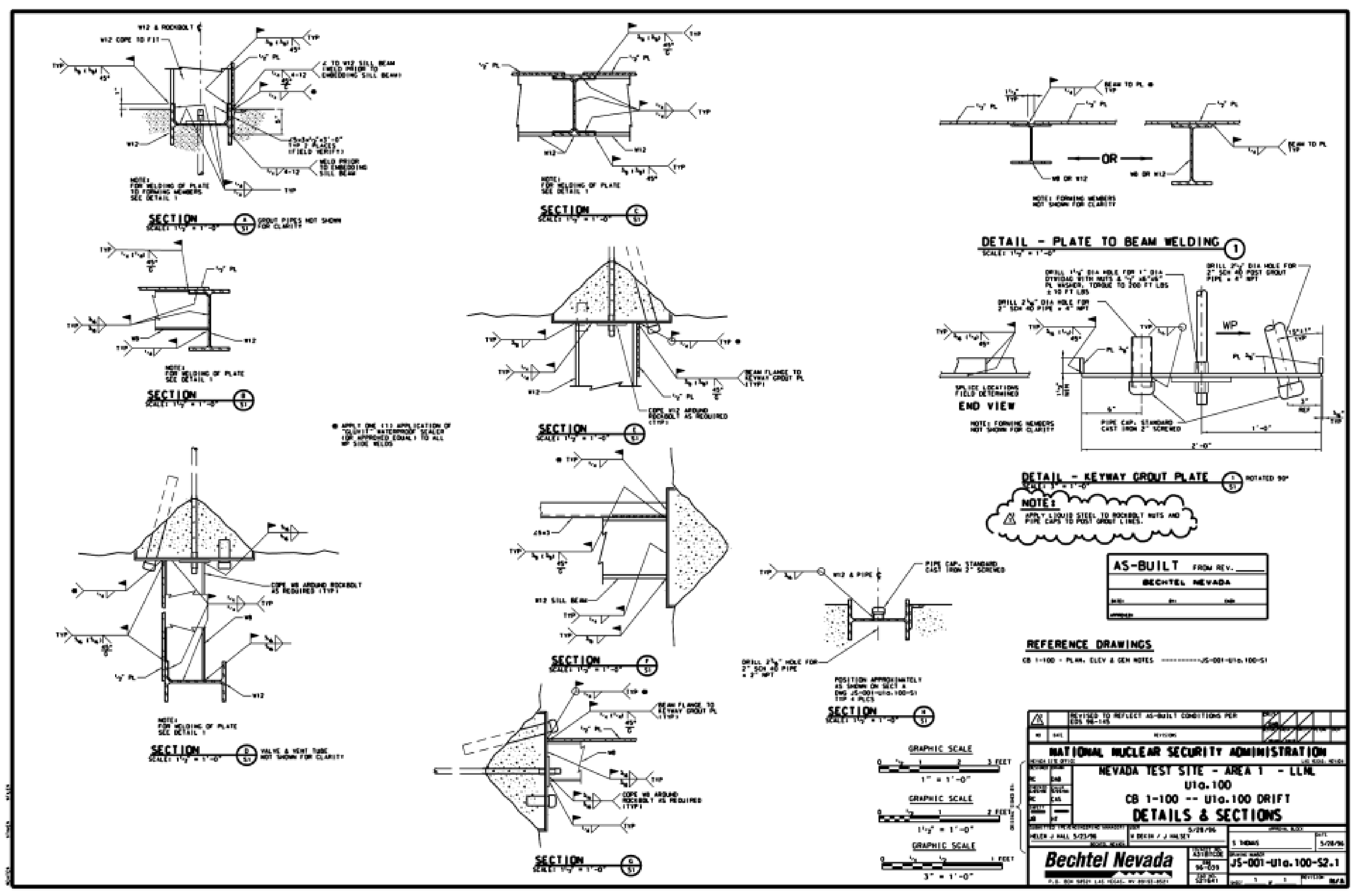

53-54 


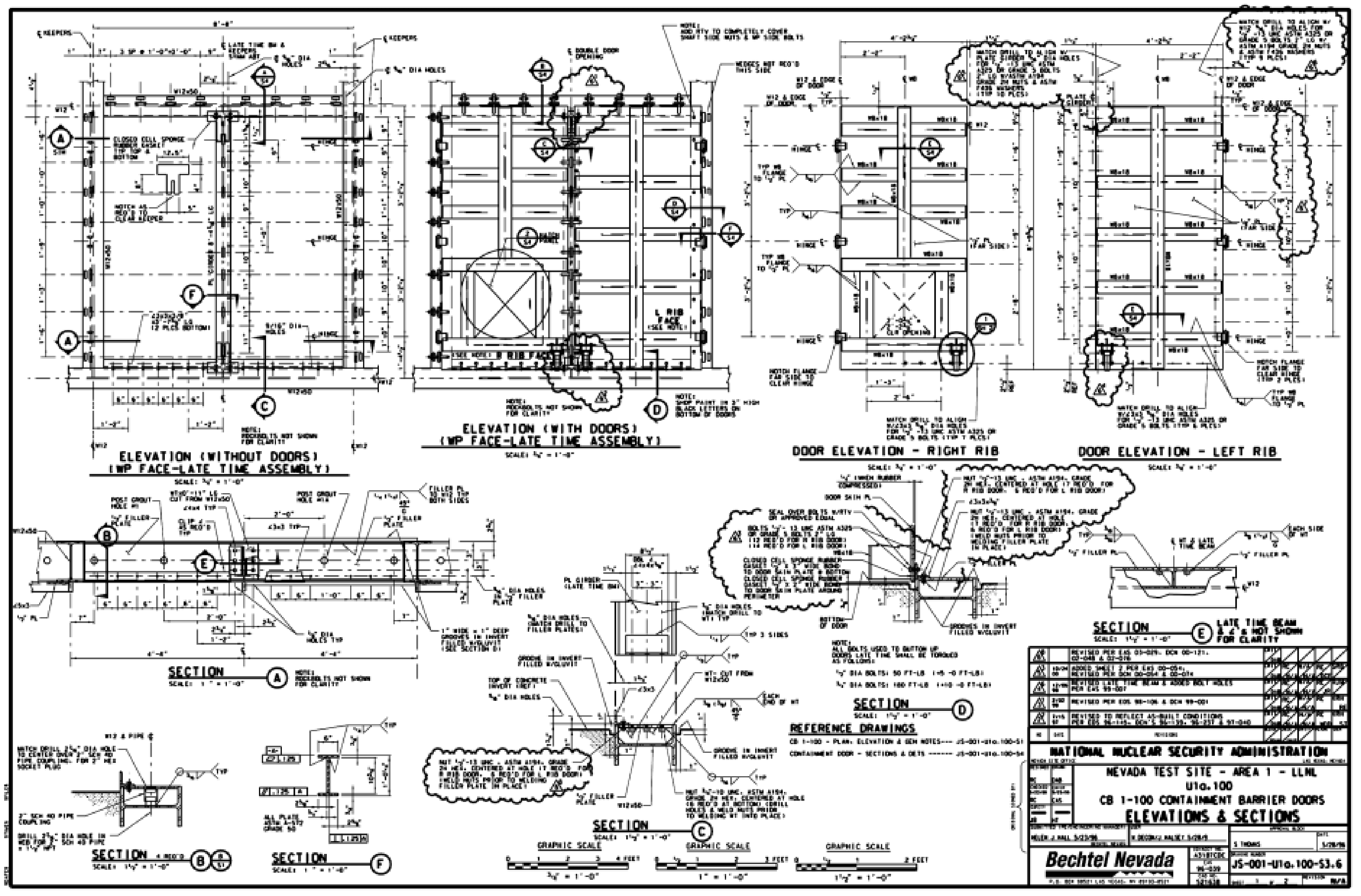




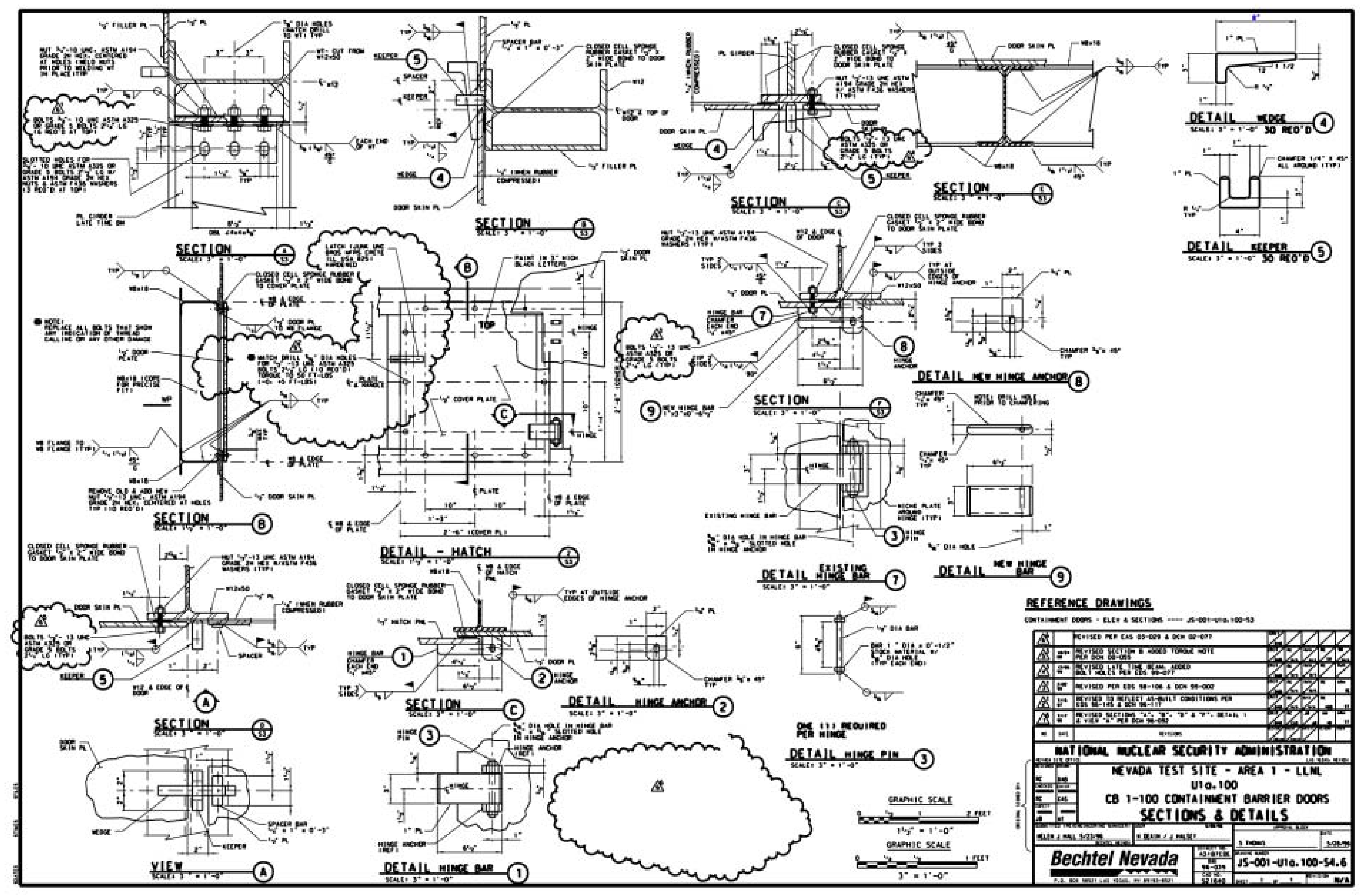




\section{Appendix D:}

\section{Optical Port Assembly Drawings}


INTENTIONALLY LEFT BLANK 


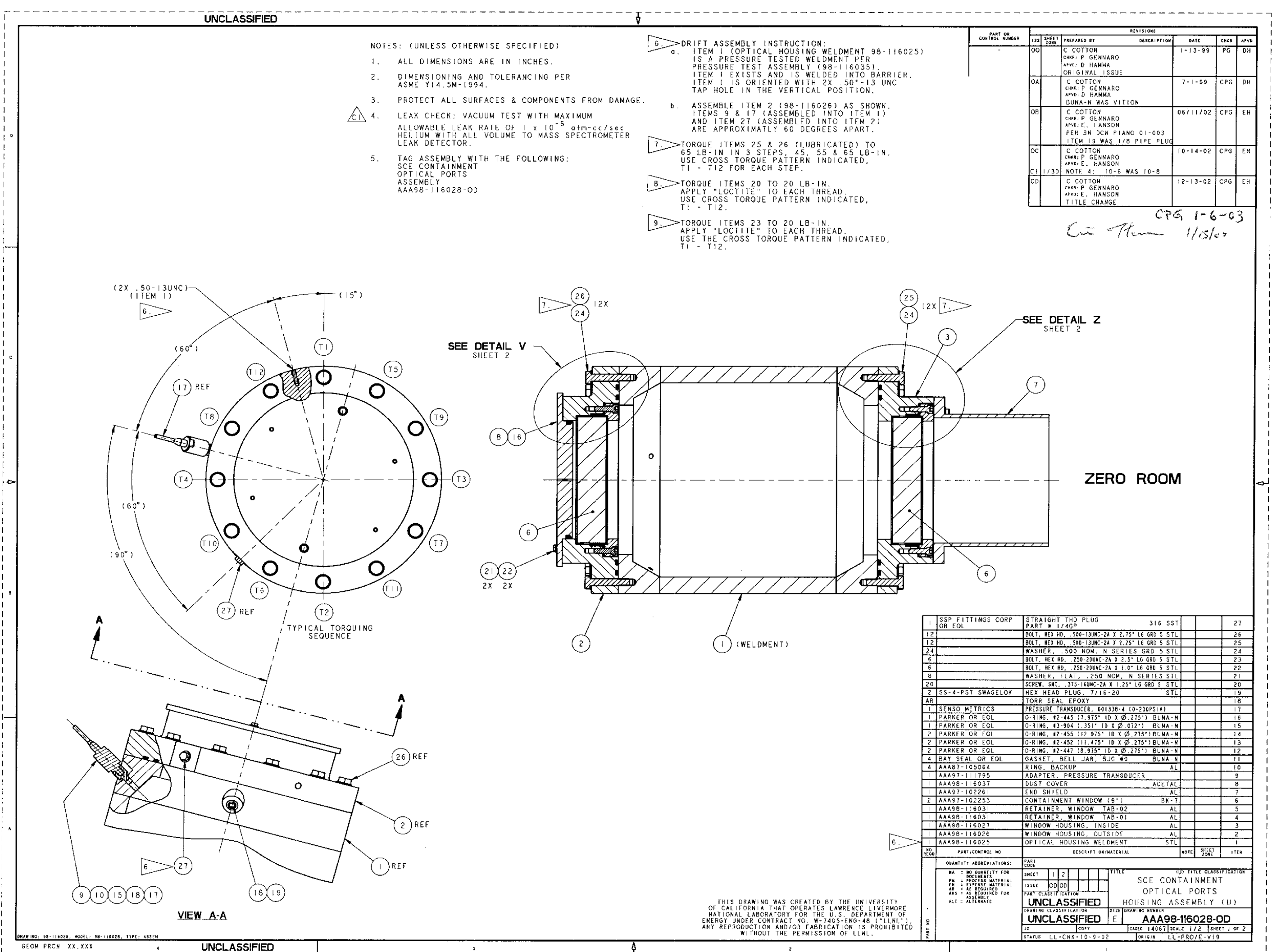




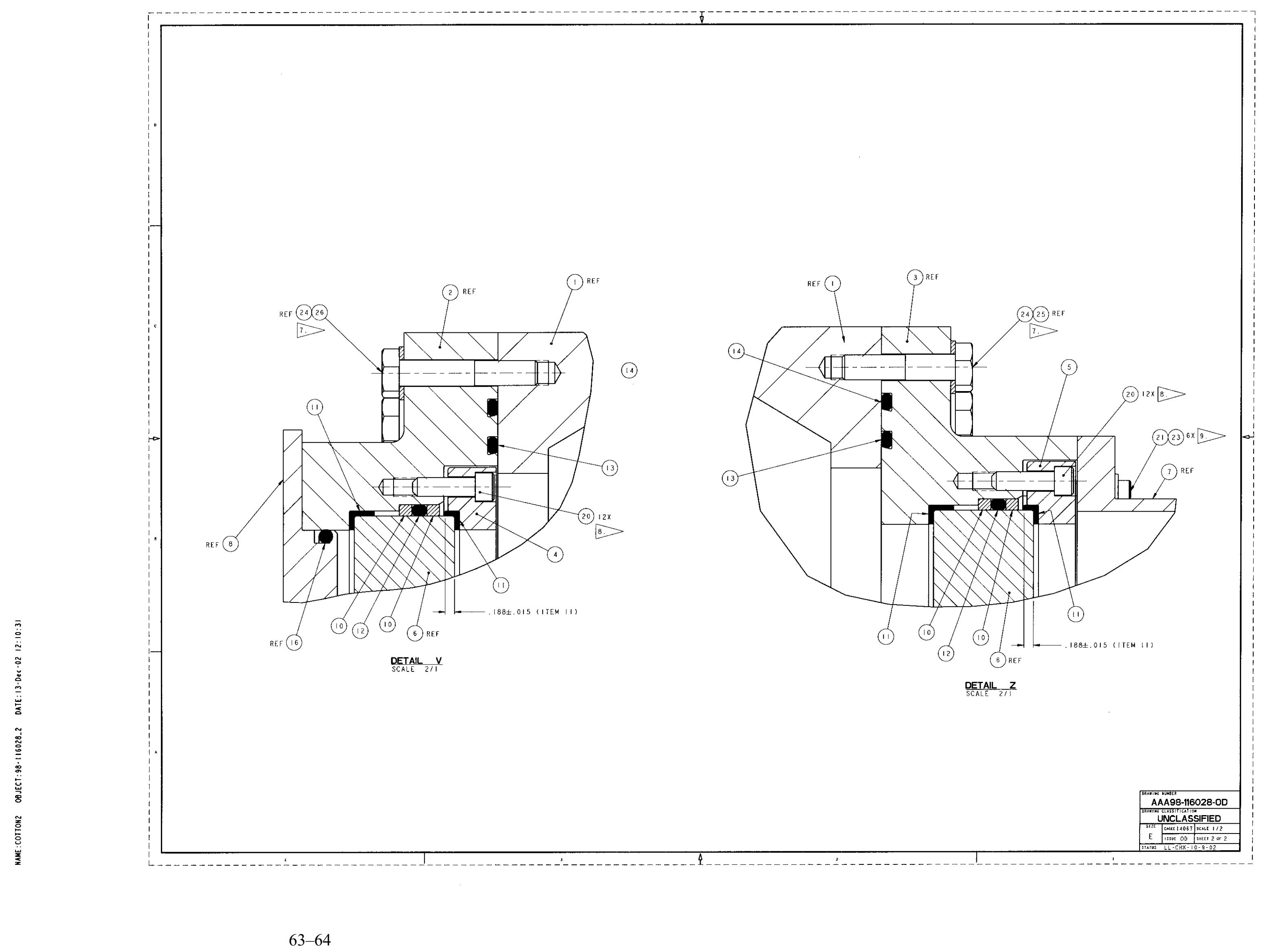




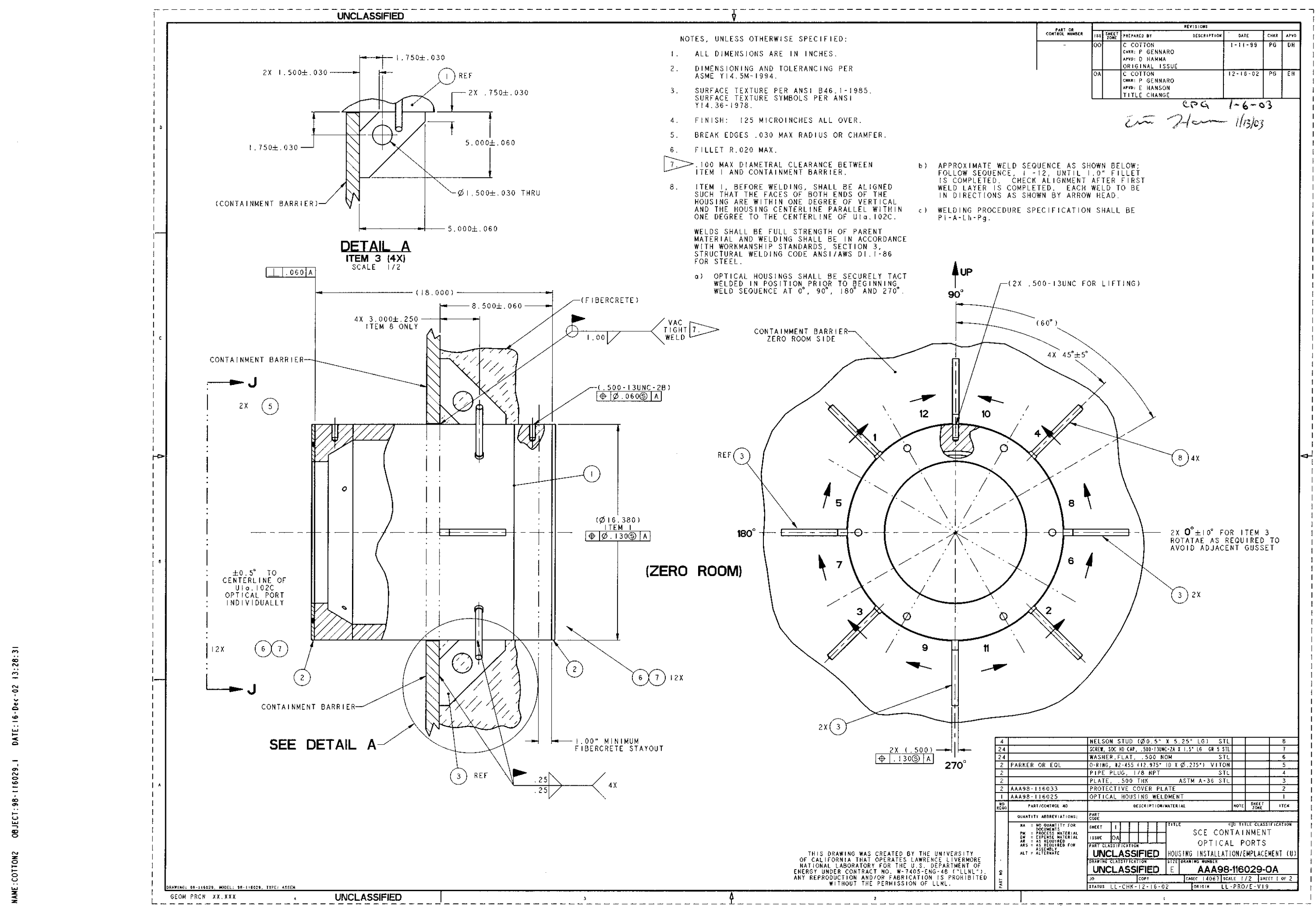




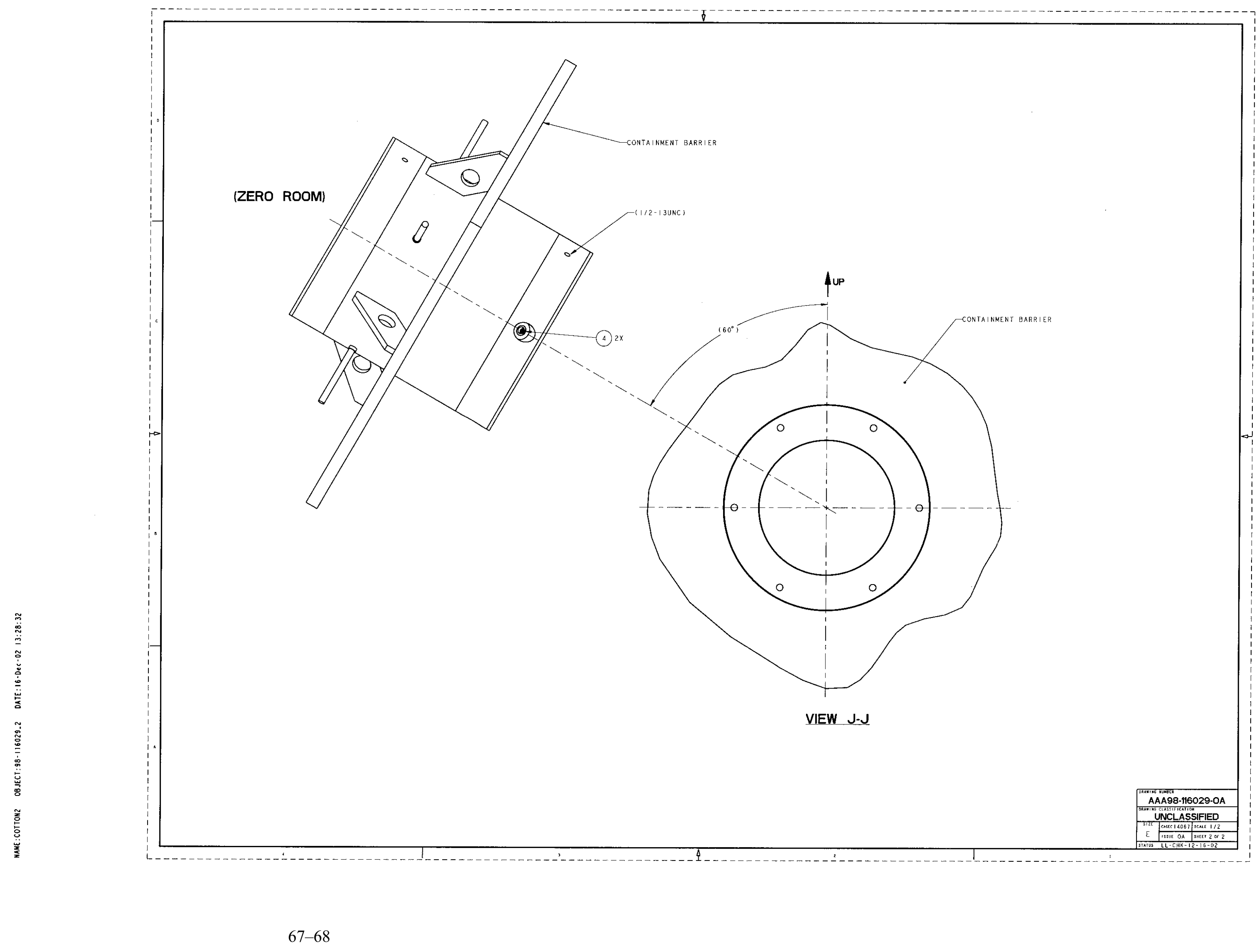

